\title{
Seasonal shelf-sea front mapping using satellite ocean colour and temperature to support development of a marine protected area network
}

\author{
Peter I. Miller, Weidong Xu and Morven Carruthers ${ }^{1}$ \\ Remote Sensing Group, Plymouth Marine Laboratory, \\ Prospect Place, Plymouth PL1 3DH, UK. \\ ${ }^{1}$ Scottish Natural Heritage, Great Glen House, \\ Inverness IV3 8NW, UK.
}

\begin{abstract}
Front detection and aggregation techniques were applied to 300m resolution MERIS satellite ocean colour data for the first time, to describe frequently occurring shelf-sea fronts near to the Scottish coast. Medium resolution $(1 \mathrm{~km})$ thermal and colour data have previously been used to analyse the distribution of surface fronts, though these cannot capture smaller frontal zones or those in close proximity to the coast, particularly where the coastline is convoluted. Seasonal frequent front maps, derived from both chlorophyll and SST data, revealed a number of key frontal zones, a subset of which were based on new insights into the sediment and plankton dynamics provided exclusively by the higher-resolution chlorophyll fronts. The methodology is described for applying colour and thermal front data to the task of identifying zones of ecological importance that could assist the process of defining marine protected areas. Each key frontal zone is analysed to describe its spatial and temporal extent and variability, and possible mechanisms. It is hoped that these tools can provide guidance on the dynamic habitats of marine fauna towards aspects of marine spatial planning and conservation.
\end{abstract}

Keywords: marine protected areas, pelagic biodiversity, shelf-seas, fronts, sea-surface temperature, ocean colour.

Article info: Miller, P.I., Xu, W. \& Carruthers, M. (in press) Seasonal shelf-sea front mapping using satellite ocean colour and temperature to support development of a marine protected area network. Deep Sea Research Part II. doi: 10.1016/j.dsr2.2014.05.013. This document is the author's post-print.

\section{Introduction}

The Marine (Scotland) Act 2010 and the UK Marine and Coastal Access Act (2009) include new powers and duties to designate Nature Conservation Marine Protected Areas (MPAs) to protect important biodiversity and geodiversity in Scotland's seas. The principles for the identification of a MPA network in Scotland's seas are set out in the MPA Selection Guidelines, which establish that fronts are one of five large-scale features included on the list of MPA search features to guide the design of the network. The other large-scale features on the list are shelf banks and mounds, shelf deeps, seamounts and continental slope. Large-scale features were included in order to help build ecosystem function into the development of the MPA network, for example through helping to identify areas of wider functional significance. Persistent hydrographic features, such as fronts, are widely recognised as supporting enhanced biological activity. Mixing at the boundary between two water bodies can lead to elevated primary and secondary production (Franks, 1992, Samuelsen et al., 2012) and as a result serve to aggregate species at higher trophic levels. There are many published studies associating marine animals with fronts (reviewed by Scales et al., submitted-b), for example fish (e.g. Bakun, 2006, Munk et al., 2009), seabirds (e.g. Bost et al., 2009) and basking sharks (Sims and Quayle, 1998). Seabirds and basking sharks are among the priority species targeted for conservation through MPAs, and frontal features were included in the 2013 MPA consultation 
in Scotland; there is ongoing work in relation to fronts and assessment of MPA search locations.

This paper utilises $300 \mathrm{~m}$ resolution ocean colour imagery in order to create mapping and interpretive products that were used to provide advice on MPAs in Scotland's seas. Frequent front maps for UK seas were previously produced, based on ocean thermal imagery at $1-3 \mathrm{~km}$ resolution and indicate on a continuous scale the percentage of time over each season that strong fronts are observed at each location (Miller and Christodoulou, 2014). These maps provide an indication of surface thermal fronts in Scotland's seas, however only fronts with surface thermal signatures were detected. Furthermore the mapping was not of sufficient resolution to capture smaller frontal zones or those in close proximity to the coast. Scotland has a particularly convoluted coastline which means that a significant proportion of frontal zones were beyond reach of these existing thermal front maps (Miller et al., 2014).

Higher resolution $(300 \mathrm{~m})$ ocean colour data are now available through Medium Resolution Imaging Spectrometer (MERIS). The aim of this project was to apply front detection to the $300 \mathrm{~m}$ ocean colour data, allowing observations of fronts much closer to the coast and within estuaries. Ocean colour products such as chlorophyll-a offer a number of benefits for observing fronts. The algae or suspended sediment acts as a tracer for physical processes, and hence may indicate fronts that only have a density gradient rather than a thermal gradient. In addition visible light is reflected back from several metres into the water column, depending on turbidity, so it is possible to observe fronts that would be obscured in sea surface temperature data by wind mixing, stratification or surface heating. Mapping fronts based on the chlorophyll signal, rather than temperature alone, may also provide a more direct indication of the enhanced primary production that can be associated with frontal areas.

\section{Methodology}

\subsection{Geographical area}

Figure 1 depicts the bathymetry surrounding Scotland, dominated by a steep continental shelf break though with many significant topographic features on the shelf within the range of 100$150 \mathrm{~m}$ depth, and islands including the Inner and Outer Hebrides, Orkney and Shetland. The study region was selected to cover a majority of the Scottish exclusive economic zone (EEZ) considered by the MPA process, extending to beyond the shelf break. The EEZ was intersected with a bounding box from 54.1 to $64.1^{\circ} \mathrm{N},-13.8$ to $3.8^{\circ} \mathrm{E}$.

\subsection{Satellite data}

\subsubsection{MERIS Full-resolution $300 \mathrm{~m}$ ocean colour}

The primary dataset for this study was the Medium Resolution Imaging Spectrometer (MERIS) sensor on board the European Space Agency (ESA) Envisat satellite, operational between March 2002 and April 2012. MERIS acquired 15 spectral bands in the 390-1040 nm range of visible to near-infrared reflectance. A global archive of 300m MERIS full-resolution (FR) data were acquired from the ESA near-real time rolling archive, as Level 2 (ESA N1 format) files containing calibrated reflectances, geophysical parameters and georeferencing data.

Queries were implemented using ESA's Earth Observation Link (EOLi) system to identify all the MERIS data granules that overlapped the study region. The matching data were located in the Plymouth Marine Laboratory (PML) data archive and processed and mapped using PML's Generic Earth Observation Processing System (GEOPS). The data were mapped to Mercator projection, giving image dimensions of 3316x3743 pixels for a minimum horizontal resolution of $300 \mathrm{~m}$ within the area.

The MERIS FR data are able to detect features closer to the coast than reduced resolution (RR) data at $1.2 \mathrm{~km}$, which are commonly used for ocean colour studies because they are more readily available. Nevertheless, there are a couple of limitations associated with use of MERIS FR data. The narrow swath width $(1150 \mathrm{~km})$ of MERIS compared to other colour sensors means that a region in mid-latitudes will be covered only every 1-2 days, rather than several times per 
day (ESA, 2011). Therefore the quantity of data available for processing was reduced. In addition the MERIS FR data are not recorded globally, but only made available for shelf-sea regions; this limited the northern extent of the data processed for this project.

Data from 2009-2011 were processed, comprising 2,600 files of MERIS FR mapped scenes. This was the entire dataset of FR data available to the authors at this time, and enabled initial study of the high-resolution frontal variability. Although this sensor is no longer operational, OLCI, a similar sensor is due for launch on ESA Sentinel-3 in 2014 (ESA, 2014).

The product considered in this study was the ESA standard chlorophyll-a (Chl-a) product, called Algal-1, a semi-empirical algorithm based on the ratios of four reflectance bands. This algorithm is designed for open ocean (Case 1) waters, but has been found to be applicable to coastal regions also, and has less noise and artefacts than the Algal-2 neural network algorithm designed for coastal (Case 2) waters (e.g. Sá et al., 2008). The colour properties of Case 1 waters are determined by the concentration of phytoplankton and its associated chlorophyll, while in Case 2 waters the colour properties are determined by other constituents such as sediment or coloured dissolved organic matter.

Although Algal-1 is designed to estimate the Chl-a concentration only, due to the inherent complexity of marine optics it will also indicate some suspended sediment features. This is an advantage for the current study, as the Algal-1 fronts will delineate both phytoplankton blooms and sediment plumes. This methodology should be robust for use on alternative Chl-a algorithms if these do not decrease the data coverage or signal to noise ratio.

\subsubsection{MODIS $1 \mathrm{~km}$ ocean colour}

Due to the limited coverage of the MERIS FR dataset, Chl-a fronts were also processed using the Moderate Resolution Imaging Spectroradiometer (MODIS) sensor on the National Aeronautics and Space Administration (NASA) Aqua satellite, launched in May 2002. This sensor covers a wider swath at $1 \mathrm{~km}$ resolution, providing 1 or 2 views of the region every day. Over 3,400 Aqua-MODIS mapped scenes were processed for 2009-2011, using the PML GEOPS processing system.

The product considered was the NASA standard Chl-a algorithm, called OC3M, which is a semi-empirical algorithm based on the maximum of three reflectance band ratios. Similarly to the MERIS Algal-1, it is calibrated using Case 1 data but has been found to be generally applicable to Case 2 waters as well.

\subsection{Detection of ocean colour fronts}

\subsubsection{Composite front map}

The next stage of processing was to detect ocean fronts on every individual Chl-a scene, and combine these to generate 8-day composite front maps. The composite front map technique combines the location, gradient, persistence and proximity of all fronts observed over a given period into a single map (Miller, 2009). This often achieves a synoptic view from a sequence of partially cloud covered scenes without blurring dynamic fronts, an inherent problem with conventional time-averaging methods. The 8-day window was selected to include sufficient cloud-free observations while preventing the merging of neighbouring dynamic fronts. It is important to emphasise that: (a) front detection is based on local window statistics specific to frontal structures (homogenous regions of distinctly different temperature), and not simply on horizontal gradients; and (b) fronts are not detected on Chl-a composites, but rather on individual Chl-a scenes that reveal the detailed structure without averaging artefacts. This front detection approach based on detecting 'edges' has been previously applied successfully to Chl-a data (e.g. Miller, 2004), but it is recognised that there are other approaches, for instance to target peaks of enhanced Chl-a along a front (Belkin and O'Reilly, 2009). To simplify the 8-day front maps for studying key frontal zones, a novel clustering algorithm was applied (Miller, unpublished data). 


\subsubsection{Extensions for higher-resolution MERIS data}

The composite front map technique includes a 'proximity' term to correctly weight persistent features that may be displaced during the 8 day compositing time period due to advection, tides, or residual geocorrection errors. To highlight such features it is necessary to consider the spatial proximity of front contours in one scene to those in other scenes. The Gaussian smoothing filter used to define the proximity was increased in width by 4 times to 8 pixels $(\sim 2.4 \mathrm{~km}$, compared to the 2 pixel width filter in Miller (2009)), to account for the higher resolution of the FR Chl-a data.

\subsection{Frequent ocean colour front maps}

\subsubsection{Frequent front maps}

As in the previous study of thermal front distribution (Miller et al., 2010) it was important to capture the spatio-temporal variability of the shelf-sea. Therefore the next stage of analysis was to aggregate the 8-day composite front maps into seasonal front climatologies to identify strong, persistent and frequently occurring features. Such frontal systems could be key factors influencing the distribution of productivity and diversity. An algorithm was developed to perform this aggregation, which estimates the percentage of time a strong front is observed within each grid location. The classification as a 'strong' front was based on exceeding a predetermined threshold based on gradient and persistence (see section 2.4.2 and 2.4.3). Each grid cell and 8-day period was analysed according to the total number of satellite passes, the number of cloud-free observations (valid if at least 1), and whether a strong front was indicated.

Frequent front maps were created by averaging the ratio of strong fronts to valid observations for each pixel for a particular season over all years. The following calendar seasons were used: winter: December to February; spring: March to May; summer: June to August; and autumn: September to November. This resulted in the percentage of time in which strong fronts occurred in that pixel in that season. As this was averaged over all years for which data are available, the bias caused by cloud cover was reduced; thus a year with only one valid winter observation for a particular pixel had an equal contribution to the final seasonal winter map as a year with valid observations on each month of the season. The final maps were visualised using a colour palette, contrast stretched to highlight the majority of the range of data values.

A data quantity metric was constructed to convey the fraction of satellite observations that were cloud-free, averaged over each season and year. This indicated seasonal and regional variation in cloud cover, and can be considered a metric of the representivity of the front statistics for each grid cell, and hence a relative measure of data confidence. For each of the seasonal and combined frequent front maps (MERIS 300m Chl-a and MODIS $1 \mathrm{~km} \mathrm{Chl-a),} \mathrm{a} \mathrm{GeoTIFF} \mathrm{raster}$ layer was generated for usage in ArcGIS.

\subsubsection{Application to higher-resolution MERIS data}

The threshold used to indicate a 'strong' front was $F_{\text {comp }} \geq 0.007$, where $F_{\text {comp }}$ is a measure of the combined front gradient and persistence (Miller, 2009). These quantities were then used to generate seasonal maps of frequent fronts and data quantity. Statistics were calculated using a $4 \times 4$ grid of the $300 \mathrm{~m}$ pixels, resulting in a final resolution of $1.2 \times 1.2 \mathrm{~km}$. This is necessary as small offsets of the same feature over the time-series will be accumulated; however, the final map still retains the unique information obtained from the $300 \mathrm{~m}$ resolution.

\subsubsection{Application to standard resolution MODIS data}

For the standard resolution MODIS Chl-a analysis, the threshold used to indicate a 'strong' front was $\mathrm{F}_{\text {comp }} \geq 0.010$. This threshold is slightly higher than for MERIS FR data, as the increased data quantity improves the differentiation of stronger fronts. Statistics were calculated using the source resolution of $1.2 \times 1.2 \mathrm{~km}$. 


\section{Results}

\subsection{Ocean colour composite front maps}

\subsubsection{Selected 8-day high-resolution chlorophyll front maps}

Selected 8-day high-resolution chlorophyll front maps provide examples of the initial stages of the MERIS front processing (section 2.3), and also demonstrate that the detection of ocean colour fronts at $300 \mathrm{~m}$ resolution is revealing novel features of physical structures in coastal and shelf seas that are beyond the capability of $1 \mathrm{~km}$ resolution thermal front maps (Figure 2). The fine resolution reveals turbulent sub-mesoscale eddies and other structures within the phytoplankton blooms. Figure 2a shows the dominant effect of strong currents on phytoplankton patchiness in the Faroe-Shetland Channel (cf. Fig. 8 in Sherwin et al., 2006). Figure $2 b$ depicts sub-mesoscale eddying patterns of surface current interactions with the Faroe Bank seamounts (labelled on Figure 1). Figure 2c displays a highly complex pattern of colour fronts associated with the slope current in the Faroe-Shetland Channel, tidal mixing fronts and phytoplankton blooms. Fronts can be seen closer to the Shetland coast and with more detailed shape using MERIS $300 \mathrm{~m}$ chl-a data (Figure 2d) than using AVHRR $1 \mathrm{~km}$ SST data (Figure $2 \mathrm{e})$.

\subsection{Ocean colour frequent front maps}

\subsubsection{MERIS high-resolution chlorophyll front metrics}

Figure 3 presents the ocean colour front frequency for each season, derived from all MERIS $300 \mathrm{~m}$ chlorophyll data 2009-2011. The colour scale indicates the average front occurrence for each location during that season, from $0 \%$ (purple) to $40 \%$ (red) of the time when not cloudcovered. The clusters and bands of green/yellow/red lines can be interpreted as zones with a higher likelihood of colour fronts at the surface, and thus potentially of greater ecological importance to certain marine animals.

Some seasonality can be inferred, mainly due to the presence of stratified / tidal-mixing fronts (e.g. south and south-west of Shetland) during spring and summer. The higher frequency of near-coastal fronts along the North Sea coast in autumn is also noteworthy, and is explored later in section 4.1.3.

The ill-defined patches of higher front frequency and large areas with no data (purple) in Figure 3 also indicate the limitations of the MERIS FR dataset. The narrow swath width reduces the repeat coverage rate and the opportunities for acquiring cloud-free data, as seen on the seasonal data quantity maps (supplementary Figure S1); and the bias towards shelf-seas acquisition has limited the northern extent of the data,. There would also be less northern coverage in autumn and winter due to the low sun angle reducing the validity of chlorophyll estimations. The spring and summer maps indicate greater data availability for the North Sea than the Atlantic shelf.

\subsubsection{Aqua-MODIS $1 \mathrm{~km}$ chlorophyll front metrics}

In order to extend the coverage of ocean colour fronts to the off-shelf parts of the study region, chlorophyll fronts were derived additionally from medium-resolution $(1 \mathrm{~km})$ Aqua-MODIS Chla data from 2009 to 2011. Figure 4 shows a comparison of ocean colour front frequency for all seasons, which improves the identification of colour front hotspots and analysis of their seasonal variations as a result of greater coverage. In particular it can be seen that colour fronts are pervasive in the east of the region during spring and summer, though there are consistent features with higher frequency that may be associated with tidal mixing fronts, islands, seamounts and banks (e.g. Firth of Forth banks and Dogger Bank - see Figure 1), or riverine influence. Note that these maps are lacking the fine scale and near-coast fronts only visible in the MERIS FR analysis, such as the North Sea, Shetland and Hebrides coastal fronts. 


\subsubsection{AVHRR $1 \mathrm{~km}$ thermal front metrics}

To facilitate comparison with the thermal front distributions generated for an earlier UK MPAs project using Advanced Very High Resolution Radiometer (AVHRR) $1 \mathrm{~km}$ sea surface temperature (SST) data between 2000-2009 (Miller et al., 2010), the Scottish part of the UK seasonal maps are reproduced in Figure 5. Greater clarity in delineating offshore frontal hotspots is achieved through thermal front maps due to the more frequent coverage from multiple satellites, and no high latitude limitation in winter. Results, validation and the application of thermal frequent front maps to the identification of MPAs are described in Miller and Christodoulou (2014).

\subsubsection{Comparison of colour and thermal front distribution}

In order to consider the significant features of all seasons in a single map, the colour and thermal front frequencies for the four seasons were averaged (Figure 6). This allows direct comparison of the ocean colour front distribution using MERIS 300m Chl-a data with the equivalent analysis using Aqua-MODIS $1 \mathrm{~km}$ Chl-a data, and with the thermal front distribution from AVHRR $1 \mathrm{~km}$ data. The following section considers the interpretation and integration of these datasets.

\section{Interpretation of shelf-sea front distributions}

\subsection{Identification of potential frontal hotspots}

\subsubsection{Visual identification of chlorophyll front hotspots}

Figure 6a shows the mean all-season high-resolution chlorophyll front distribution, overlaid with blue rectangles enclosing six key frontal zones described in this paper. Selection was based on visual analysis of the seasonal and combined colour front maps described in section 3.2, and discussions during a workshop on fronts for the Scottish MPA project (at Heriot Watt University in March 2012), which also considered overlap with existing MPA search locations. This figure does not attempt to define the precise boundaries of these zones; the EO data for each zone are analysed and described in the following sections. For brevity, the most informative EO products are shown for each zone rather than all possible products.

\subsubsection{Frontal zone 1: Aberdeenshire to Firth of Forth}

Figure 7 summarises the spatial distribution of thermal and colour fronts in this region. This frontal zone can be defined as extending from the coast out to the limit of the green region $(>35 \%)$ on the thermal front frequency map (Figure 7a). These thermal fronts appear to correspond to a narrow shallower inner shelf (Figure 1), and so may be associated with enhanced tidal mixing. Note that the low frequency band (dark blue/purple) near the coast indicates the limit of front detection using coarser $1.2 \mathrm{~km}$ SST data. The MERIS $300 \mathrm{~m}$ combined frequency map (Figure 7b) allows hotspots to be identified within this zone, such as east Aberdeenshire and the southern coast of the Firth of Forth, areas already known for high abundance of cetaceans (Cheney et al., 2013) and pinnipeds (Sharples et al., 2009).

There is considerable seasonal variation of these fronts: in autumn and winter the thermal fronts are focused near to the coast, whereas in spring and summer the stratification generates additional surface fronts that extend much further offshore (Figure 5). Colour fronts are mainly present in spring and summer (Figure 4), though near-coastal fronts are particularly obvious in autumn (Figure 3).

Figure 8 provides example MERIS FR data to explain the mechanisms for certain fronts that occur in this region during spring. The Chl-a composite (Figure 8a) depicts a significant phytoplankton bloom extending into the North Sea that appears to be intensified along the coast. However, the enhanced colour version (Figure 8b), which stretches the blue-green part of the visible spectrum to fill the blue-red range, discriminates between the bloom offshore (green/brown colour) and suspended sediment along the coast (yellow/orange colour). As explained above, the Chl-a algorithm will often overestimate the concentration when there is 
also sediment in the water; though this actually assists the analysis as both Chl-a and sediment fronts are of interest. There appears to be a coastal process that is retaining the sediment from east coast rivers in a narrow band; this may relate to the thermal front seen there (Figure 6c), or to a density front caused by the riverine input of freshwater. It is likely that a boundary of turbid water would have a structuring effect on a fish community due to the impact of turbidity on prey and predator visibility (Utne-Palm, 2002).

The original and simplified Chl-a front maps (Figure 8c-d) delineate the main colour fronts present during the 8-day period and indicates the high and low (red-blue) sides of the front. Off the tip of north-east Aberdeenshire there are two distinct fronts, the inner front more related to sediment and the outer front resulting from a bloom. Both of these colour features correspond to peaks of thermal front frequency (50-60\% during spring), and both coincide with bathymetric features that may cause local changes in mixing efficiency. Further examples of the coastal sediment fronts in this region have been studied in different seasons (not shown here).

\subsubsection{Frontal zones 2: Fair Isle and 3: North-west of Shetland}

Figure 9 shows enlarged sections of the summer thermal and colour front frequency for the Orkney and Shetland region. The strong tidal currents through this region generate well defined fronts separating mixed and stratified water (Inall et al., 2009). It can be seen that several of these predictable Chl-a fronts correspond to thermal fronts (Figure 5), in particular the band that extends north-to-south a short distance east of Fair Isle (Pingree, 1977).

The seasonal variability of these fronts corresponds to the strength of stratification, so the fronts are most prominent in spring and summer, though still present for part of autumn and winter (Figure 5).

Figure 10 explores the Chl-a features around Fair Isle using 8-day MERIS FR composites from two summers. In the first example there is a plankton bloom south and east of Shetland which is restricted to remain to the east of the tidal mixing front near Fair Isle; this is indicated by the presence of colour fronts with the low side toward Fair Isle (Figure 10a \& b). This contrasts with the second example in which the island is contained within a bloom that extends south past Orkney, and so the fronts show the opposite polarity with the island on the high side (Figure $10 \mathrm{c} \& \mathrm{~d}$ ). These two snapshots are not representative of the overall biological variability or patchiness, but do at least indicate that the plankton distribution is much more variable than the physical structures. This enforces the results of the seasonal comparison in which the Chl-a fronts (Figure 9b) were observed with variable frequency (10-40\%) throughout this region. The high-resolution Chl-a frontal analysis revealed another smaller region close to the northwest coast of Shetland that had not been observed previously using coarser Earth observation (EO) data. This zone is apparent during summer (Figure 9b), and appears to correspond to fine scale features seen in individual weeks (e.g. Figure 10c). This suggests that small fronts are arising quite regularly in this location during summer.

\subsubsection{Frontal zone 4: Galloway peninsula and Clyde sill}

The fourth frontal zone of interest encompasses the Galloway peninsula and north to the Clyde sill (Figure 11). The high-resolution Chl-a fronts were of particular value in this zone, revealing a highly persistent colour feature close to the west coast and extending south towards Isle of Man and east around the south of the peninsula further offshore. At the Clyde sill (Figure 1) the frequent thermal front corresponds to a less frequent colour front.

The thermal and colour fronts are present throughout the year (Figure 3, Figure 4, Figure 5), which points to an estuarine front caused by salinity differences between the Clyde and Solway firths and the Irish Sea.

An example 8-day period in autumn is explored in Figure 12: the enhanced colour image (Figure 12b) shows high suspended sediment concentrations throughout Solway Firth, and perhaps advecting north along the west Galloway coast. There is a slight increase in phytoplankton along the Clyde sill. Hence in this region the thermal fronts indicate more biological activity in terms of primary production, and the colour fronts are more associated with sediment processes. 


\subsubsection{Frontal zones 5: South-west of Tiree, and 6: Uist, Hebrides}

Figure 13 shows that the fronts observed south-west of Tiree are primarily thermal: though there is a slightly increased frequency in the Aqua-MODIS $1 \mathrm{~km}$ Chl-a fronts. This could be explained by the position of Chl-a fronts being more variable than the physical features, or a low surface chl-a concentration; in some areas the deep Chl-a maximum will be more significant for marine animals, and such features cannot be detected using EO data (Scott et al., 2010). The distance of this front from Tiree is related to the shallow inner shelf that extends south-west from the island and causes tidal mixing (Figure 1). It is also possible that upwelling could occur off such a submerged promontory. The thermal front is usually present during spring and summer (Figure 5).

Occasionally, however, an ocean colour front is observed south-west of Tiree, such as this example during April 2011 (Figure 14), where there is a sharp contrast between the nutrientrich shelf water and clearer oceanic water during the spring bloom.

The 300m Chl-a fronts also revealed higher frequency along the outer coast of North and South Uist, Outer Hebrides (Figure 13b). This may be as a result of coastal sediments (Figure 14b), rather than enhanced concentration of phytoplankton, probably due to resuspension by the strong wave regime on this exposed Atlantic coast.

\section{Discussion}

The key frontal zones were selected through detailed analysis of the seasonal chlorophyll and thermal front distributions. However, the limitations of Earth observation data prevent this from being viewed as a complete and objective list of important frontal zones. Such limitations include cloud cover, and the omission of deep Chl-a maxima, and are detailed below. There is a possibility that deep Chl-a maxima may occasionally be visible to EO, for example where topographic features cause internal waves that force the thermocline up towards the surface. However, such events will be transient, so are unlikely to be indicated on the seasonal maps. It should be appreciated that the Chl-a front maps delineate a mixture of both chlorophyll and sediment boundary features (for example Figure $11 \mathrm{~b}, \mathrm{c}$ ). This is because both properties may be influenced by the same physical process, and also that the chlorophyll algorithm may not entirely distinguish between these coloured constituents. For future work it would be possible to perform a similar frontal analysis on a time-series of EO-derived suspended sediment concentration, as this may confirm which are truly sediment features, and those can be discounted from the Chl-a fronts.

Each of the key frontal zones was illustrated using example 8-day maps of ocean colour, Chl-a, or Chl-a fronts, in order to depict certain short-term processes which contribute to the seasonal front distribution. However, these snapshots should not be taken as representative of the whole season, due to the dynamic variability of shelf-sea processes, and also that their selection was necessarily biased towards periods of lower cloud cover. Only the seasonal front frequency maps (Figure 3, Figure 4, Figure 5) should be viewed as representative of the frontal distribution for the whole season.

All infrared and visible EO data are limited by cloud cover, though the composite front map techniques optimise the visualisation of fronts by combining all observations derived from sequences of partially cloudy scenes. Cloud cover may lead to biases in data analysis, for instance if features such as upwelling or stratification fronts are correlated with clear skies; however, this paper is based on sufficient data to minimise such biases.

Currently the resolution of most global monitoring thermal and colour sensors is limited to $1 \mathrm{~km}$, so there is a lack of useable SST and Chl-a data within a few kilometres of the coast. The MERIS 300m Chl-a data have addressed this issue, though suffer from their own limited repeat rate and variable coverage. The narrow swath width for the MERIS data restricted the amount of cloud-free data that could be acquired for the three years studied, and this limited the statistical descriptions of frontal hotspots for the near-coastal regions.

MERIS FR data are only acquired within a certain distance from major coastlines, as these data were originally envisaged only for coastal applications, and acquisition is limited to 
approximately $40 \%$ of each orbit. It can be seen on Figure 6a that this has caused a lack of data in the northern part of the study region in all seasons, and also low data quantity in the west, over the deeper water off the shelf. Hence the noisy red lines in these regions shown in Figure 3 and Figure 6a should be considered with low confidence. Front frequency was masked for regions in which there was less than $2 \%$ temporal coverage during that season (supplementary Figure 1).

Satellites only observe surface fronts, though strong and persistent surface fronts usually indicate a depth profile through the whole surface layer. Ocean colour is retrieved from only the top few metres of the sea, depending on turbidity, and so deep Chl-a maxima (e.g. at the thermocline depth of perhaps $20-50 \mathrm{~m}$ ) will not be visualised. It should be remembered that these subsurface features are known to be of importance to fish and diving animals such as seals (Scott et al., 2010).

There are also methodological implications of the approach, in its assumption that fronts are correlated with increased abundance and biodiversity of pelagic animals. This is a simplification of complex bio-physical interactions, in which each marine taxon reacts to fronts to a varying degree, for different aspects of their life cycle or survival strategy. Nevertheless, there are a multitude of published studies on the influence of fronts on commercial fish, mammals and seabirds (Podesta et al., 1993, Tynan et al., 2005, Bost et al., 2009, Munk et al., 2009). The techniques presented here allow for much wider application of fronts to conservation issues, and additional studies of particular species distributions are now underway with the aim of further increasing confidence in this approach.

It would be of considerable value to relate these new findings on shelf-sea fronts to datasets of animal tracks gained from tagging, for example seabirds, seals and basking sharks. PML scientists are developing geostatistical approaches to explore the relationships between marine animals and ocean fronts (e.g. Scales et al., submitted-a); these techniques could be focussed on the key frontal zones identified in this project in order to further our understanding of their potential wider functional importance on the continental shelf. Readers should contact the corresponding author if interested in accessing this front dataset.

A further issue is whether past front distribution will be representative of future locations. The approach indicates the spatial and temporal variability within the time-series, and most frequent fronts are likely to be due to tidal mixing that is tied to bathymetry. However, other fronts could possibly shift according to changing climate, winds or currents. Hence further work should consider reasons why fronts occur at certain locations, for example by comparison with hydrodynamic model simulations.

\section{Conclusions}

Front detection and aggregation techniques were successfully applied to higher-resolution $(300 \mathrm{~m})$ satellite ocean colour data for the first time, to describe frequently occurring Chl-a and sediment fronts near to the Scottish coast. Seasonal frequent front maps, derived from both chlorophyll and SST data, revealed key frontal zones, six of which are described in this paper. Two of these zones were identified based on new insights into the sediment and plankton dynamics provided by the higher-resolution Chl-a data. The methodology for identifying potential front zones involved detailed analysis and comparison of patches where Chl-a or thermal fronts occurred more frequently in the seasonal and combined maps. The correspondence between colour and thermal fronts was considered only in terms of their seasonal distributions; further research is underway using contemporaneous frontal data to explore biophysical interactions caused by mesoscale and tidal processes, and hence expand our ecological insights. A combination of thermal and colour fronts would also increase confidence in their detected locations.

Many researchers have determined that fronts are related to the abundance and diversity of pelagic species (reviewed by Scales et al., submitted-b), and hence may be considered a proxy for pelagic diversity. EO data also have high spatio-temporal coverage and fine spatial resolution, which is lacking for many other diversity, abundance and habitat datasets (Wilson, 
2011). Hence the identified frontal zones are potentially of ecological importance and may assist in the identification of MPAs (Embling et al., 2012).

Each key frontal zone was analysed to describe its spatial and temporal extent and variability, and to discuss possible mechanisms for its existence. This involved searching through the dataset for examples of ocean colour 'snapshots' that helped to explain the phytoplankton and sediment processes which generated the front. This research has demonstrated clear benefits of the novel use of $300 \mathrm{~m}$ ocean colour data for describing shelf-sea front distributions: frontal systems were revealed close to the coastline that were not detectable using $1 \mathrm{~km}$ resolution thermal or colour data; and the maps observed sub-mesoscale aspects of shelf-sea physical processes. The combined usage of thermal and colour front distributions provides a more comprehensive analysis of persistent physical and biological processes. The algae or suspended sediment acts as a tracer for physical processes, and hence may indicate fronts that only have a density gradient rather than a thermal gradient. Also, visible light is reflected back from several metres into the water column, so may observe fronts that would be obscured in SST by wind mixing, stratification or surface heating.

The MERIS $300 \mathrm{~m}$ data were limited in terms of the repeat rate and spatial coverage, and so an additional dataset of medium-resolution $(1 \mathrm{~km})$ ocean colour data was also analysed for fronts, in order to increase the data coverage of the Scottish study region. In total over 6,000 satellite ocean colour scenes were processed from 2009 to 2011.

The outputs from this research complement and improve upon the thermal front distribution maps produced for the UK MPA project, in order to provide more comprehensive products to inform the Scottish MPA project. Alongside other available evidence, the products have been used to support the identification of an MPA proposal at the entrance to the Clyde Sea, as well as two MPA search locations; one in the area from Skye to Mull, and a second off the Aberdeenshire coast (SNH and JNCC, 2012). Further work is underway to assess the functional significance of fronts in these locations, including basking shark tagging work and habitat modelling for both cetaceans and basking shark. It is proposed that specific frontal features will only be included in Nature Conservation MPAs where evidence is available to suggest that they contribute to ecosystem function.

More broadly, several studies are underway on the distribution of different marine megafauna taxa in relation to fronts, in order to increase the evidence for these relationships (e.g. Oppel et al., 2012). It is hoped that these tools can provide guidance in many aspects of marine spatial planning and conservation.

\section{Acknowledgements}

This research was funded by Scottish Natural Heritage. Satellite data were received and processed by the NERC Earth Observation Data Acquisition and Analysis Service

(NEODAAS) at Dundee University and Plymouth Marine Laboratory (www.neodaas.ac.uk). Envisat-MERIS data courtesy ESA. Aqua-MODIS data courtesy NASA OceanColor Web. The GEBCO Digital Atlas published by the British Oceanographic Data Centre on behalf of IOC and IHO, 2003. The authors thank 4 anonymous reviewers for helpful comments.

\section{References}

Bakun, A. (2006) Fronts and eddies as key structures in the habitat of marine fish larvae: opportunity, adaptive response and competitive advantage. Scientia Marina, 70, 105122.

Belkin, I.M. \& O'Reilly, J.E. (2009) An algorithm for oceanic front detection in chlorophyll and SST satellite imagery. Journal of Marine Systems, 78(3), 319-326.

Bost, C.A., Cotté, C., Bailleul, F., Cherel, Y., Charrassin, J.B., Guinet, C., Ainley, D.G. \& Weimerskirch, H. (2009) The importance of oceanographic fronts to marine birds and mammals of the southern oceans. Journal of Marine Systems, 78(3), 363-376.

Cheney, B., Thompson, P.M., Ingram, S.N., Hammond, P.S., Stevick, P.T., Durban, J.W., Culloch, R.M., Elwen, S.H., Mandleberg, L., Janik, V.M., Quick, N.J., Islas- 
Villanueva, V., Robinson, K.P., Costa, M., Eisfeld, S.M., Walters, A., Phillips, C., Weir, C.R., Evans, P.G.H., Anderwald, P., Reid, R.J., Reid, J.B. \& Wilson, B. (2013) Integrating multiple data sources to assess the distribution and abundance of bottlenose dolphins Tursiops truncatus in Scottish waters. Mammal Review, 43(1), 71-88.

Embling, C.B., Illian, J., Armstrong, E., van der Kooij, J., Sharples, J., Camphuysen, K.C.J. \& Scott, B.E. (2012) Investigating fine-scale spatio-temporal predator-prey patterns in dynamic marine ecosystems: a functional data analysis approach. Journal of Applied Ecology, 49(2), 481-492.

ESA (2011) MERIS User Guide. http://earth.esa.int/envisat/handbooks/meris/CNTR1.htm.

ESA (2014) SENTINEL-3 OLCI User Guide. https://earth.esa.int/web/sentinel/userguides/sentinel-3-olci.

Franks, P.J.S. (1992) Sink or swim - accumulation of biomass at fronts. Marine Ecology Progress Series, 82(1), 1-12.

Inall, M., Gillibrand, P., Griffiths, C., MacDougal, N. \& Blackwell, K. (2009) On the oceanographic variability of the North-West European Shelf to the West of Scotland. Journal of Marine Systems, 77(3), 210-226.

Miller, P.I. (2004) Multispectral front maps for automatic detection of ocean colour features from SeaWiFS. International Journal of Remote Sensing, 25(7-8), 1437-1442, doi:10.1080/01431160310001592409.

Miller, P.I. (2009) Composite front maps for improved visibility of dynamic sea-surface features on cloudy SeaWiFS and AVHRR data. Journal of Marine Systems, 78(3), 327336, doi:10.1016/j.jmarsys.2008.11.019.

Miller, P.I. \& Christodoulou, S. (2014) Frequent locations of oceanic fronts as an indicator of pelagic diversity: Application to marine protected areas and renewables. Marine Policy, 45, 318-329. doi: 10.1016/j.marpol.2013.09.009

Miller, P.I., Christodoulou, S. \& Saux-Picart, S. (2010) Oceanic thermal fronts from Earth observation data - a potential surrogate for pelagic diversity. Report to the Department of Environment, Food and Rural Affairs. Defra Contract No. MB102. Plymouth Marine Laboratory, subcontracted by ABPmer, Task 2F, Report No. 20., pp.24.

Miller, P.I., Xu, W. \& Lonsdale, P. (2014) Seasonal shelf-sea front mapping using satellite ocean colour to support development of the Scottish MPA network. Scottish Natural Heritage Commissioned Report No. 538. pp.33.

Munk, P., Fox, C.J., Bolle, L.J., Van Damme, C.J.G., Fossum, P. \& Kraus, G. (2009) Spawning of North Sea fishes linked to hydrographic features. Fisheries Oceanography, 18(6), 458-469.

Oppel, S., Meirinho, A., Ramírez, I., Gardner, B., O'Connell, A.F., Miller, P.I. \& Louzao, M. (2012) Comparison of five modelling techniques to predict the spatial distribution and abundance of seabirds. Biological Conservation, 156, 94-104, doi: 10.1016/j.biocon.2011.11.013.

Pingree, R.D. (1977) Phytoplankton growth and tidal fronts around British-Isles. TransactionsAmerican Geophysical Union, 58(9), 889-889.

Podesta, G.P., Browder, J.A. \& Hoey, J.J. (1993) Exploring the association between swordfish catch rates and thermal fronts on United-States longline grounds in the Western NorthAtlantic. Continental Shelf Research, 13(2-3), 253-277.

Sá, C., Da Silva, J., Oliveira, P.B. \& Brotas, V. (2008) Comparison of MERIS (algal-1 and algal-2) and MODIS (OC3M) chlorophyll products and validation with HPLC in situ data collected off the western Iberian Peninsula. 2nd MERIS/(A)ATSR User Workshop; Frascati. 666 SP. European Space Agency.

Samuelsen, A., Hjollo, S.S., Johannessen, J.A. \& Patel, R. (2012) Particle aggregation at the edges of anticyclonic eddies and implications for distribution of biomass. Ocean Science, 8(3), 389-400. 
Scales, K.L., Miller, P.I., Embling, C.B., Ingram, S.N., Pirotta, E. \& Votier, S.C. (submitted-a) Mesoscale fronts as foraging habitats: composite front mapping reveals oceanographic drivers of habitat use for a pelagic seabird. Journal of the Royal Society Interface.

Scales, K.L., Miller, P.I., Hawkes, L.A., Ingram, S.N., Sims, D.W. \& Votier, S.C. (submitted-b) On the front line: frontal zones as priority conservation areas in a dynamic management paradigm for mobile marine vertebrates. Journal of Applied Ecology.

Scotı, B.E., Sharples, J., Ross, O.N., Wang, J., Pierce, G.I. \& Camphuysen, C.J. (2010) Subsurface hotspots in shallow seas: fine-scale limited locations of top predator foraging habitat indicated by tidal mixing and sub-surface chlorophyll. Marine EcologyProgress Series, 408, 207-226.

Scottish Natural Heritage \& Joint Nature Conservation Committee (2012) Advice to Scottish Government on the selection of Nature Conservation Marine Protected Areas (MPAs) for the development of the Scottish MPA network. Scottish Natural Heritage Commissioned Report No. 547.

Sharples, R.J., Arrizabalaga, B. \& Hammond, P.S. (2009) Seals, sandeels and salmon: diet of harbour seals in St. Andrews Bay and the Tay Estuary, southeast Scotland. Marine Ecology Progress Series, 390, 265-276.

Sherwin, T.J., Williams, M.O., Turrell, W.R., Hughes, S.L. \& Miller, P.I. (2006) A description and analysis of mesoscale variability in the Faroe-Shetland Channel. Journal of Geophysical Research-Oceans, 111(C3), C03003.

Sims, D.W. \& Quayle, V.A. (1998) Selective foraging behaviour of basking sharks on zooplankton in a small-scale front. Nature, 393(6684), 460-464.

Tynan, C.T., Ainley, D.G., Barth, J.A., Cowles, T.J., Pierce, S.D. \& Spear, L.B. (2005) Cetacean distributions relative to ocean processes in the northern California Current System. Deep-Sea Research Part Ii-Topical Studies in Oceanography, 52(1-2), 145167.

Utne-Palm, A.C. (2002) Visual feeding of fish in a turbid environment: Physical and behavioural aspects. Marine and Freshwater Behaviour and Physiology, 35(1-2), 111128.

Wilson, C. (2011) The rocky road from research to operations for satellite ocean-colour data in fishery management. Ices Journal of Marine Science, 68(4), 677-686.

\section{Figure legends}

Figure 1. Bathymetry map of Scottish waters, with shaded depth contours in metres, and selected features of interest labelled. This was generated using the GEBCO_08 global 30 arc-second grid, based on quality-controlled ship depth soundings and satellite-derived gravity data.

Figure 2. $\quad$ Selected 8-day MERIS 300m chlorophyll front maps, depicting sub-mesoscale detail of offshore and shelf-break fronts. 8 days ending on: (a) 08 May 2011, Shetland; (b) 27 Jul. 2011, Faroes; (c) 03 Jul. 2011, Scotland to Faroes, and (d) Shetland region enlarged; (e) comparison with AVHRR 1.1km thermal fronts for same region and period as $(\mathrm{d})$.

Figure 3. Seasonal analysis of ocean colour front frequency, derived from MERIS 300m chlorophyll data 2009-2011. Colour scale has been stretched to enhance frequencies in the range 0 to $40 \%$ (the percentage of time for which a strong front was observed). The clusters and bands of green/yellow/red lines can be interpreted as zones with a higher likelihood of colour fronts at the surface.

Figure 4. Seasonal analysis of ocean colour front frequency, derived from MODIS $1 \mathrm{~km}$ chlorophyll data 2009-2011. Frequent colour fronts are present in the North Sea during spring and summer. Near coastal colour fronts are less evident at 
this resolution. Colour scale enhances range 0 to $40 \%$ (the percentage of time for which a strong front was observed).

Figure 5. Seasonal analysis of ocean thermal front frequency, derived from AVHRR $1 \mathrm{~km}$ SST data 2000-2009.

Figure 6. Comparison of colour and thermal front distribution, using mean front frequency across four seasons, derived from (a) MERIS 300m Chl-a data 20092011. Colour fronts occur with above average frequency in areas including the Aberdeenshire coast, Luce Bay and the Mull of Galloway and to the west of Uist. Colour scale enhances range 0 to $25 \%$ (the percentage of time for which a strong front was observed). Blue squares indicating key frontal zones described in this paper. (b) MODIS 1km chlorophyll data 2009-2011.Colour scale enhances range from 0 to 30\%. (c) AVHRR $1 \mathrm{~km}$ SST data 2000-2009.

Figure 7. Mean all-seasons front frequency for Aberdeenshire-Firth of Forth: (a) thermal fronts; (b) 300m Chl-a fronts; (c) $1 \mathrm{~km}$ Chl-a fronts.

Figure 8. Analysis of colour fronts in Aberdeenshire/Firth of Forth region using 14-21 March 2011 MERIS FR composites: (a) chlorophyll-a; (b) enhanced colour; (c) 300m Chl-a composite front map; (d) simplified Chl-a front map using redblue to indicate the high-low side of each front. Chlorophyll-a and enhanced colour composites are created using different combinations of ocean colour channels, with the latter version giving a 'true' colour view. Different channels have different missing values, therefore areas with 'no data' are inconsistent between the two versions.

Figure 9. Summer front frequency for Fair Isle region: (a) thermal fronts; (b) 300m Chl-a fronts; (c) $1 \mathrm{~km}$ Chl-a fronts.

Figure 10. Analysis of colour fronts around Fair Isle using MERIS FR composites: (a) 1219 Jul. 2010 chlorophyll-a; (b) simplified Chl-a front map; (c) 26 Jun.-03 Jul 2011 chlorophyll-a; (d) simplified Chl-a front map.

Figure 11. Mean all-seasons front frequency for Galloway peninsula:

(a) thermal fronts; (b) $300 \mathrm{~m} \mathrm{Chl-a} \mathrm{fronts;} \mathrm{(c)} 1 \mathrm{~km}$ Chl-a fronts.

Figure 12. Analysis of colour fronts around Galloway peninsula and Clyde using 22-29 Sep. 2010 MERIS FR composites: (a) chlorophyll-a; (b) enhanced colour; (c) simplified Chl-a front map.

Figure 13. Mean all-seasons front frequency for Tiree and Hebrides: (a) thermal fronts; (b) $300 \mathrm{~m}$ Chl-a fronts; (c) $1 \mathrm{~km} \mathrm{Chl-a} \mathrm{fronts.}$

Figure 14. Analysis of colour fronts around Tiree and Hebrides using 23-30 Apr. 2011 MERIS FR composites: (a) Chl-a; (b) enhanced colour; (c) simplified Chl-a front map.

Supplementary Figure S1. Seasonal data quantity for MERIS 300m ocean colour data: the percentage of satellite observations that were cloud-free. There is a lack of data (purple- blue) in the far north and west areas of the study region and relatively more data (red-yellow) available for areas of the North Sea, especially during spring and summer. 


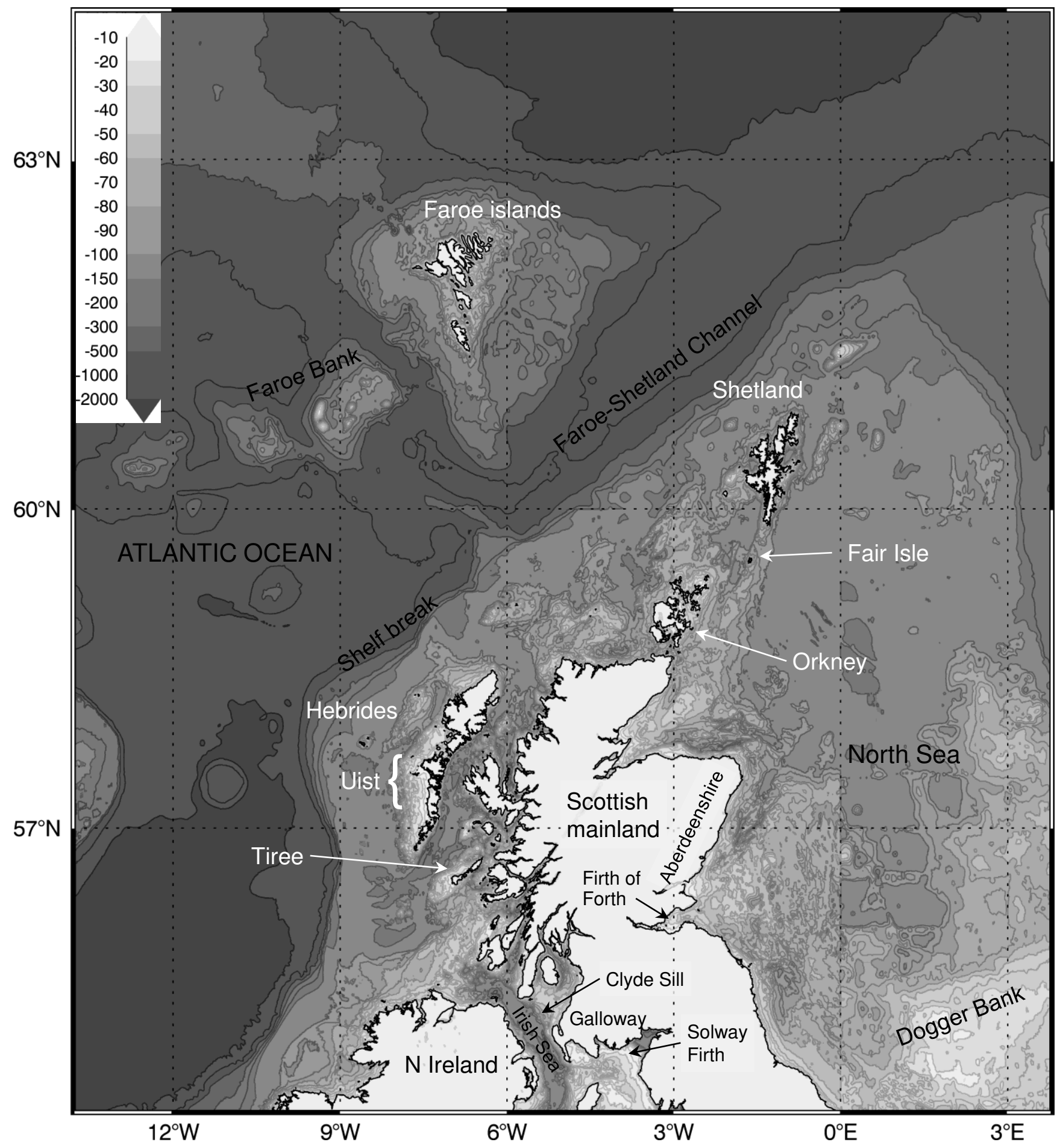

Figure 1. Bathymetry map of Scottish waters, with shaded depth contours in metres, and selected features of interest labelled. This was generated using the GEBCO_08 global 30 arc-second grid, based on qualitycontrolled ship depth soundings and satellite-derived gravity data. 


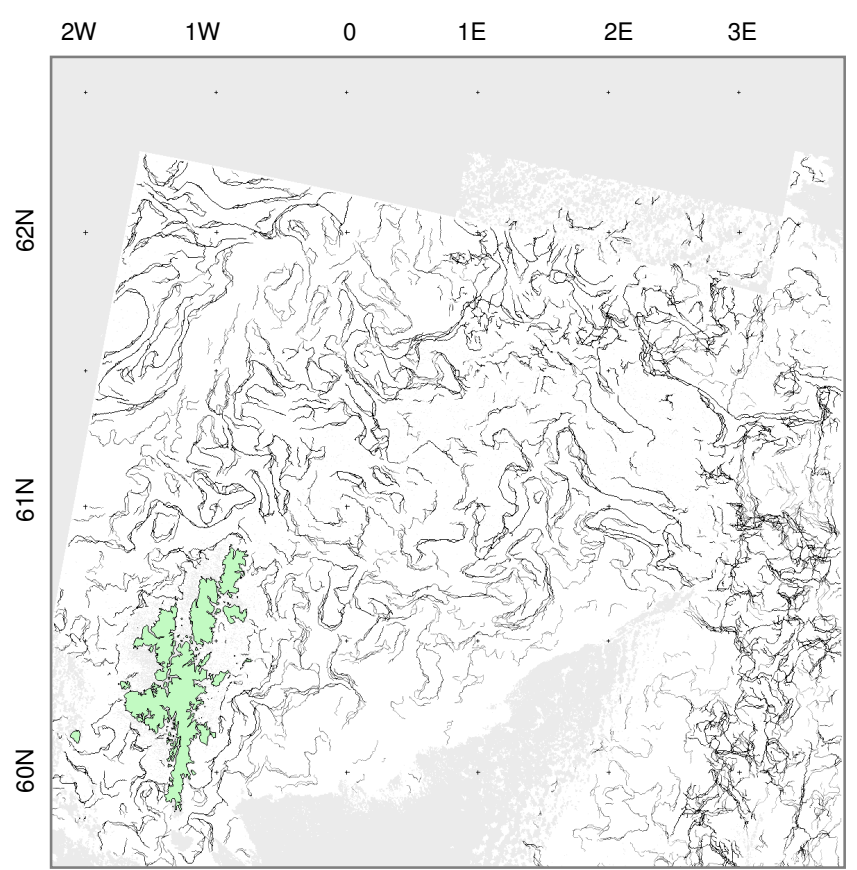

(a)

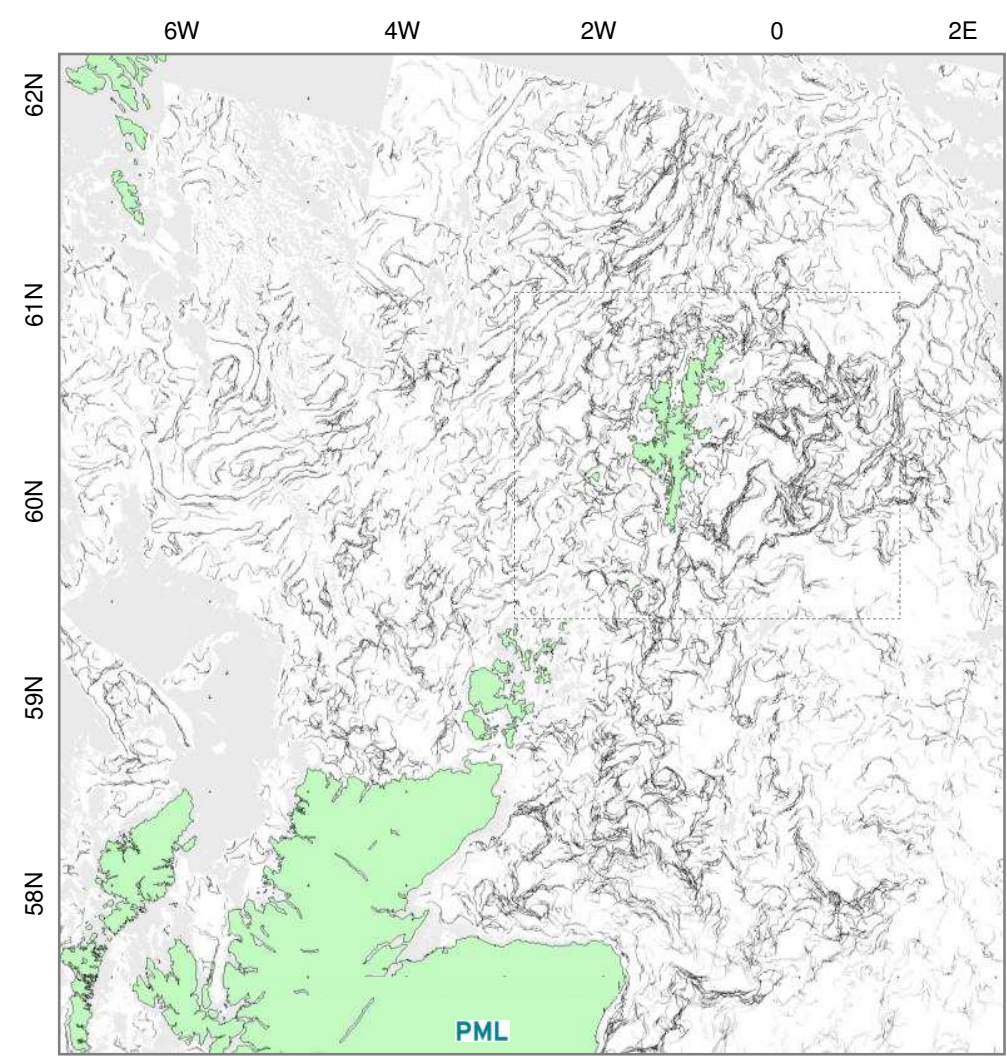

(c)

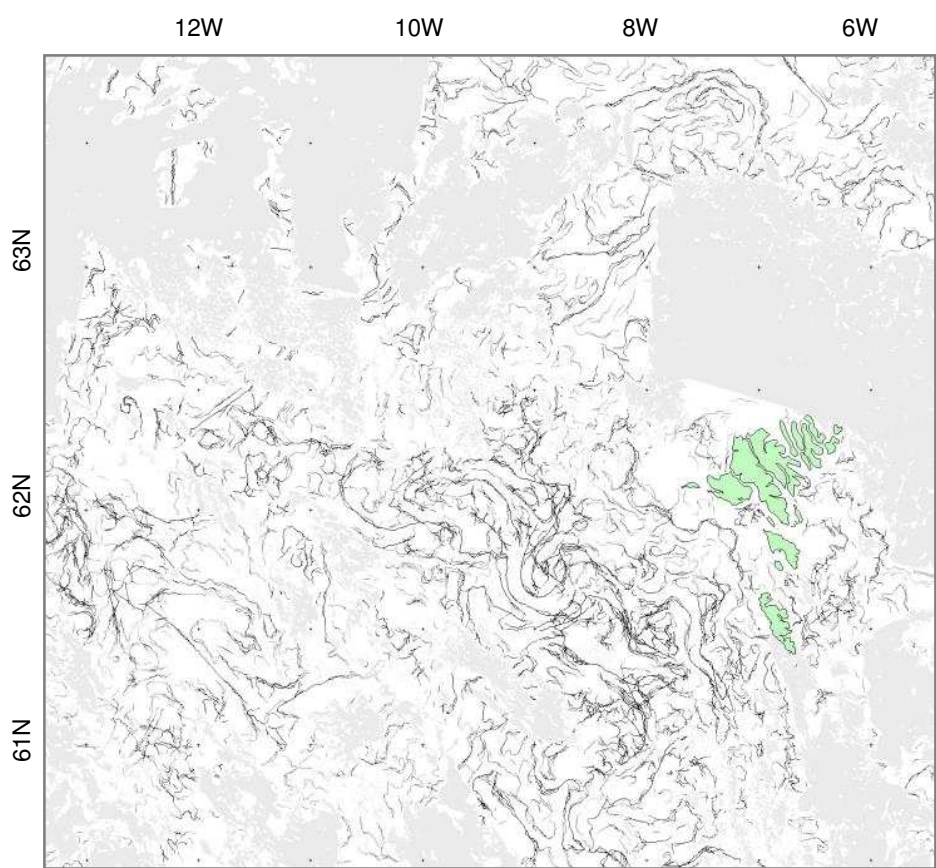

(b)

(d)

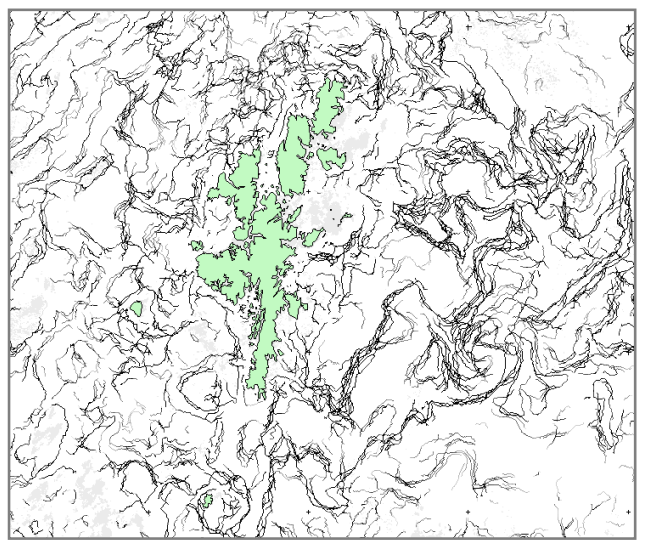

(e)

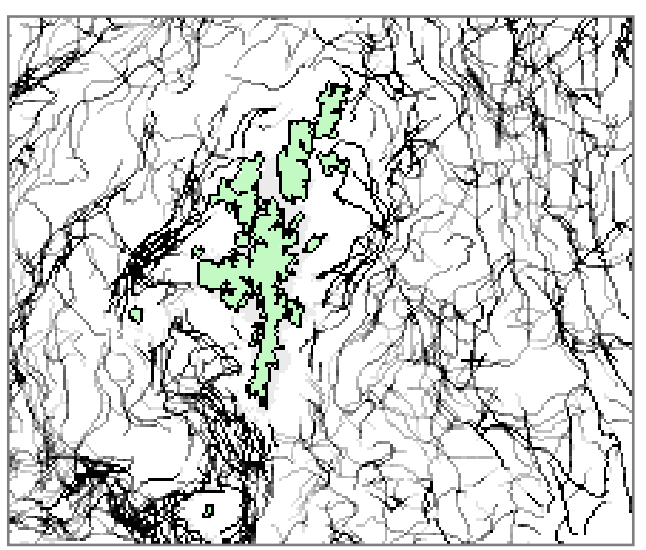

Figure 2. Selected 8-day MERIS 300m chlorophyll front maps, depicting sub-mesoscale detail of offshore and shelf-break fronts. 8 days ending on: (a) 08 May 2011, Shetland; (b) 27 Jul. 2011, Faroes; (c) 03 Jul. 2011, Scotland to Faroes, and (d) Shetland region enlarged; (e) comparison with AVHRR $1.1 \mathrm{~km}$ thermal fronts for same region and period as (d). 


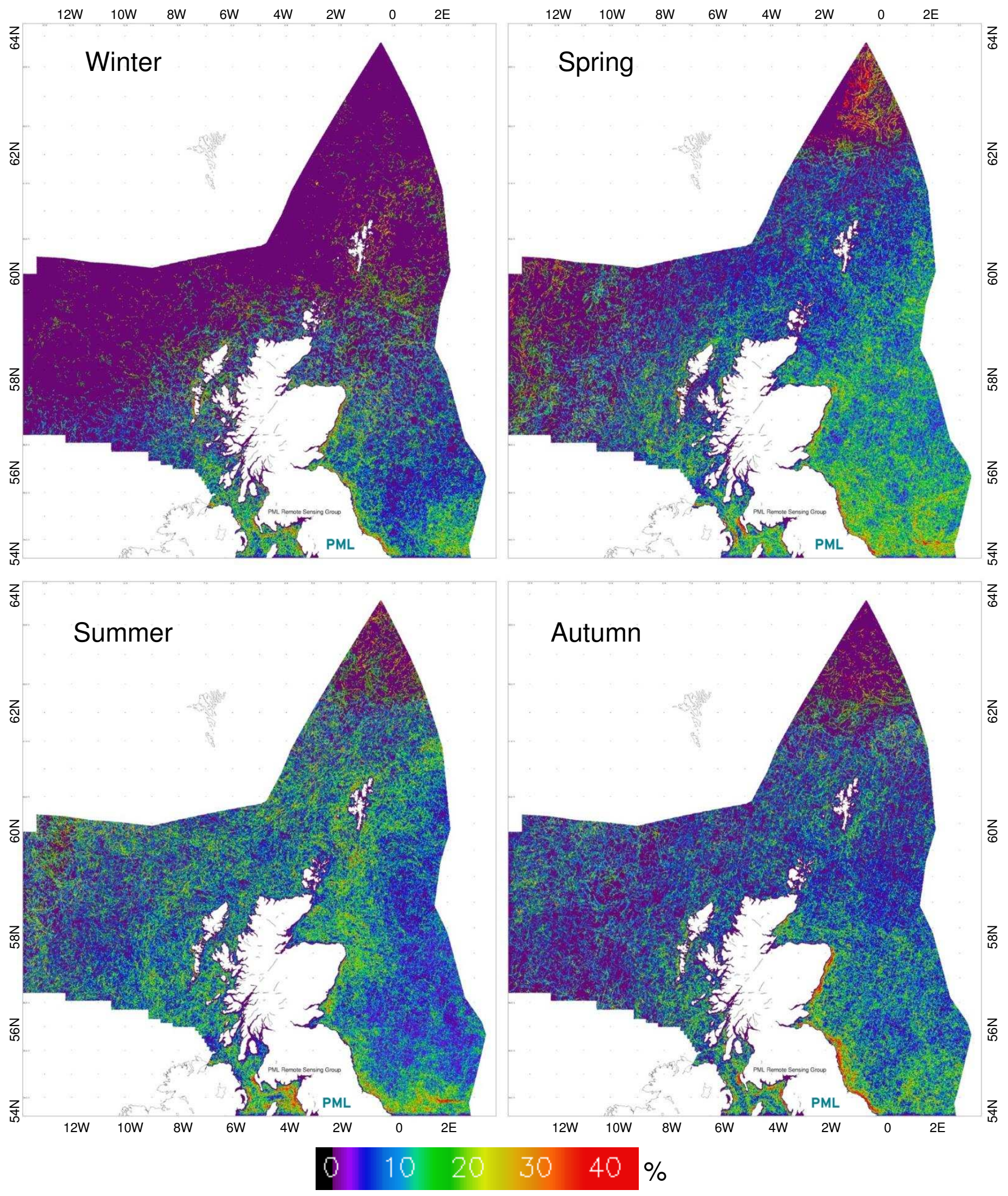

Figure 3. Seasonal analysis of ocean colour front frequency, derived from MERIS 300m chlorophyll data 2009-2011. Colour scale has been stretched to enhance frequencies in the range 0 to $40 \%$ (the percentage of time for which a strong front was observed). The clusters and bands of green/yellow/red lines can be interpreted as zones with a higher likelihood of colour fronts at the surface. 


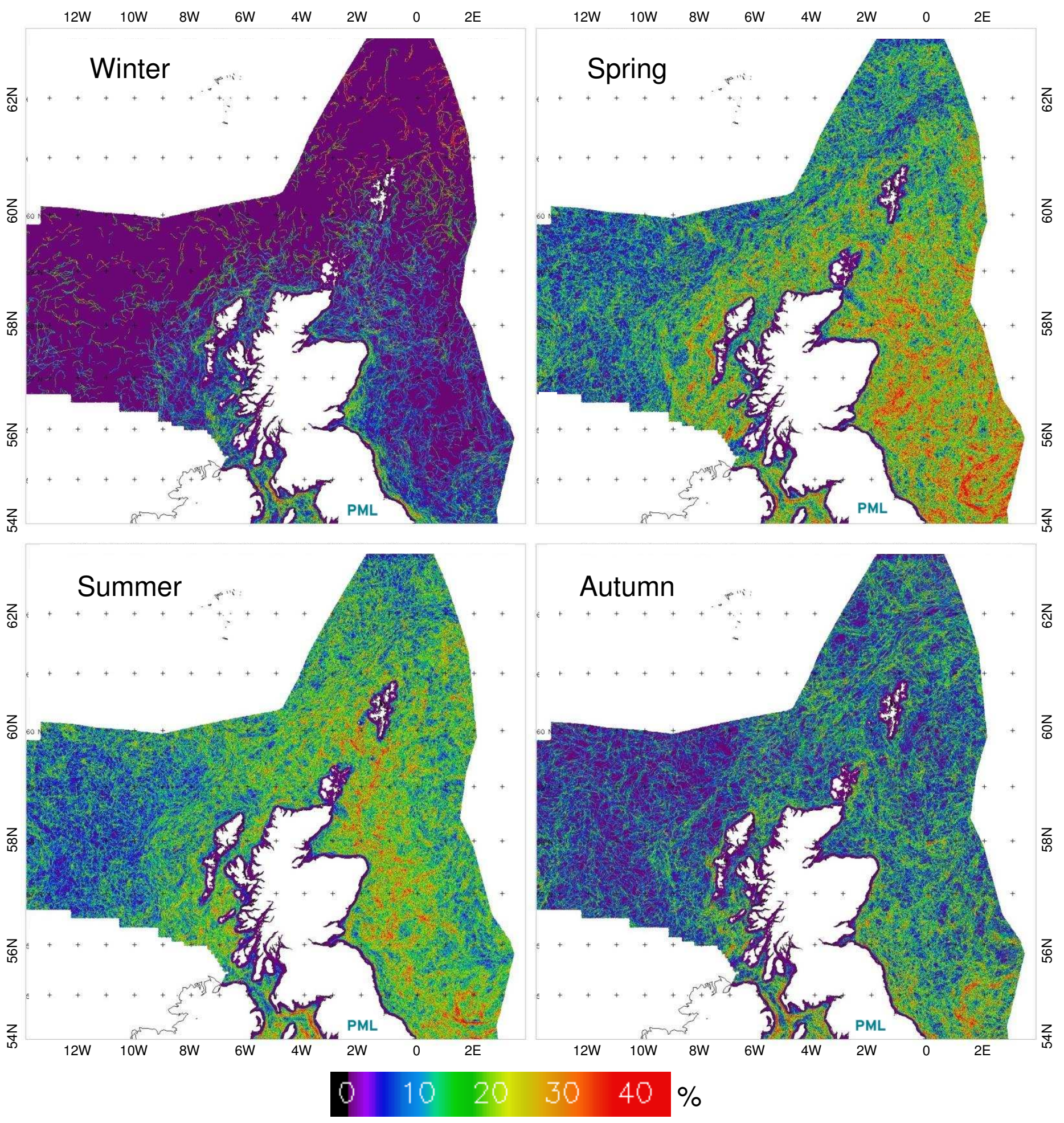

Figure 4. Seasonal analysis of ocean colour front frequency, derived from MODIS $1 \mathrm{~km}$ chlorophyll data 20092011. Frequent colour fronts are present in the North Sea during spring and summer. Near coastal colour fronts are less evident at this resolution. Colour scale enhances range 0 to $40 \%$ (the percentage of time for which a strong front was observed). 


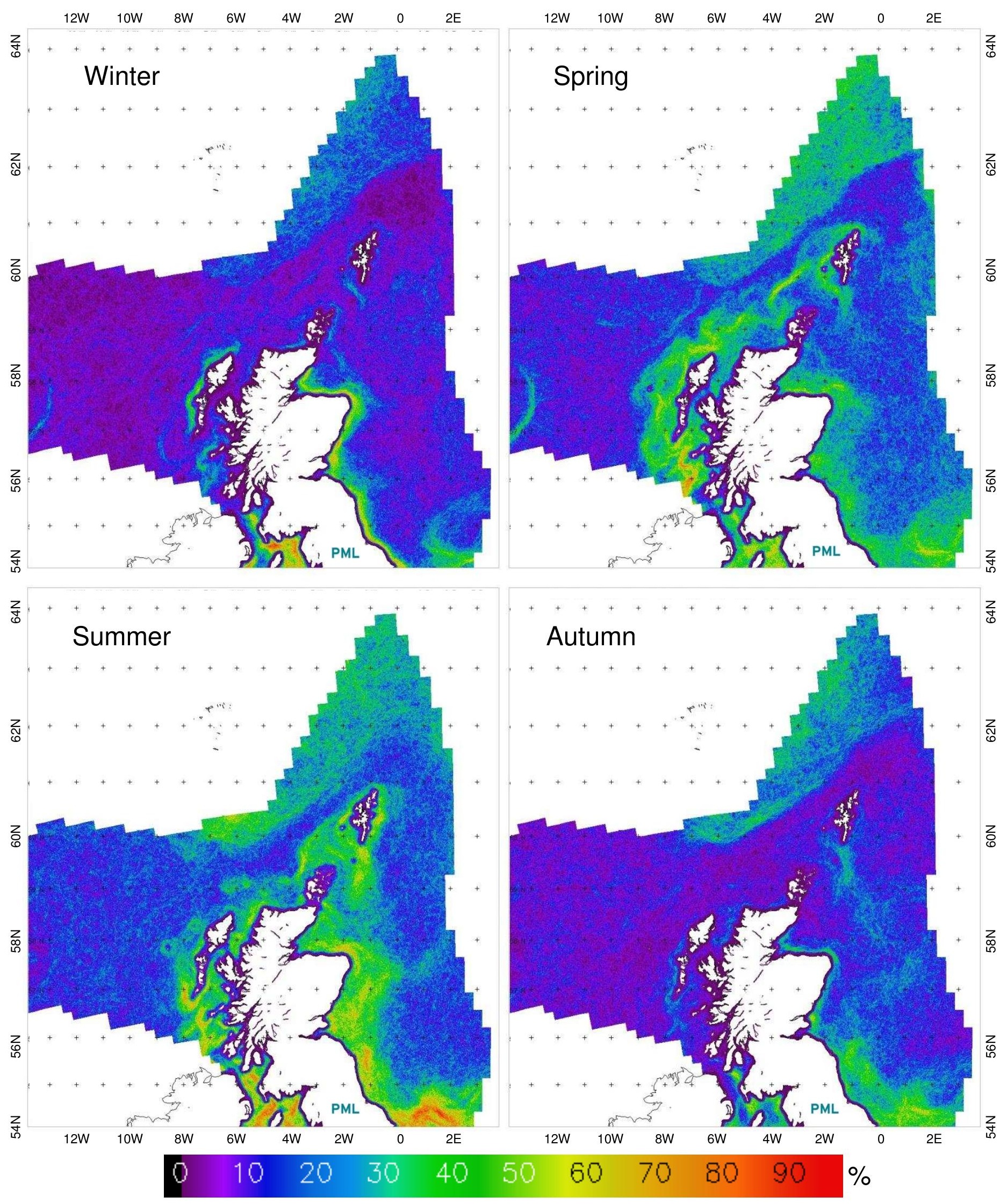

Figure 5. Seasonal analysis of ocean thermal front frequency, derived from AVHRR 1km SST data 2000-2009. 


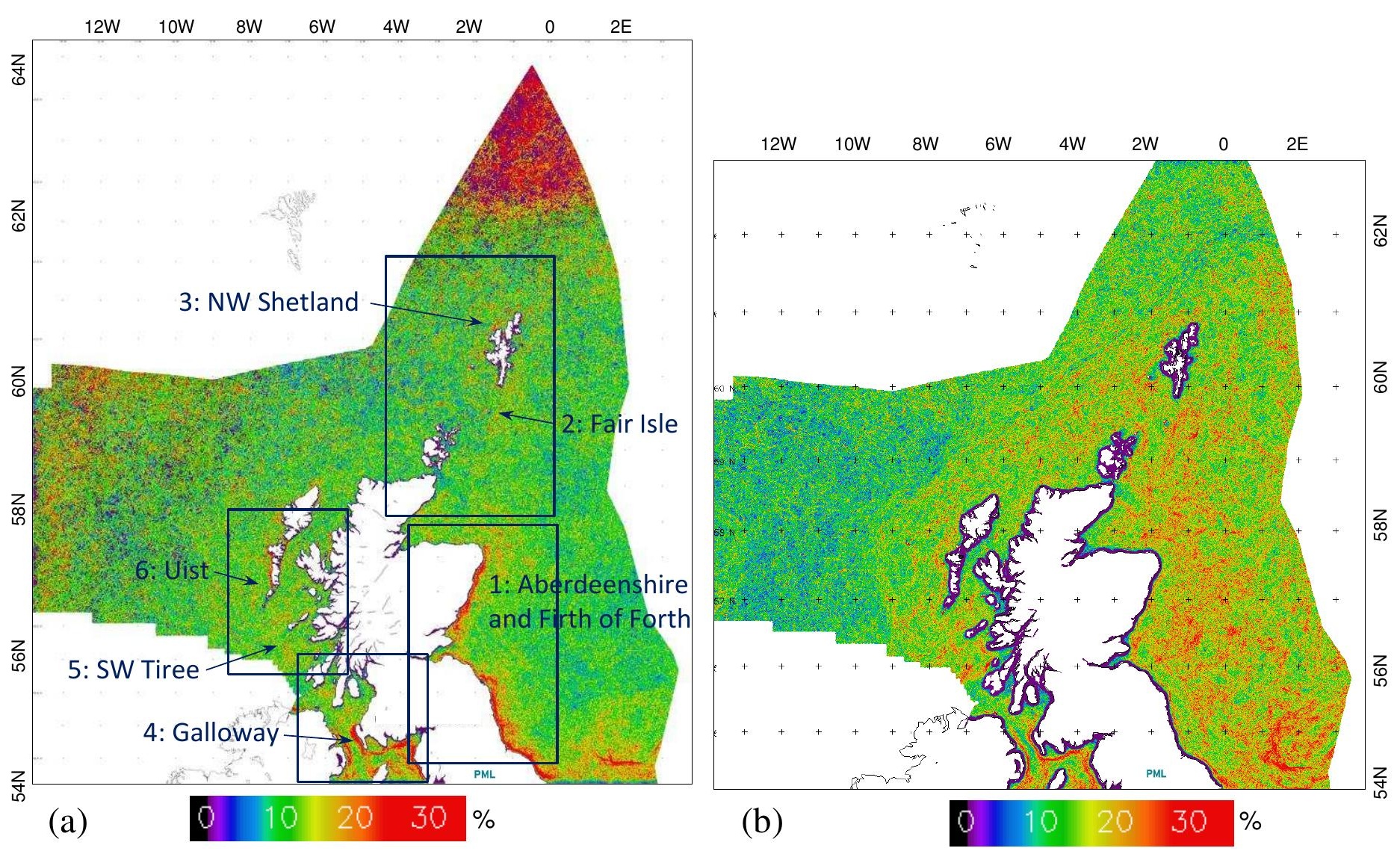



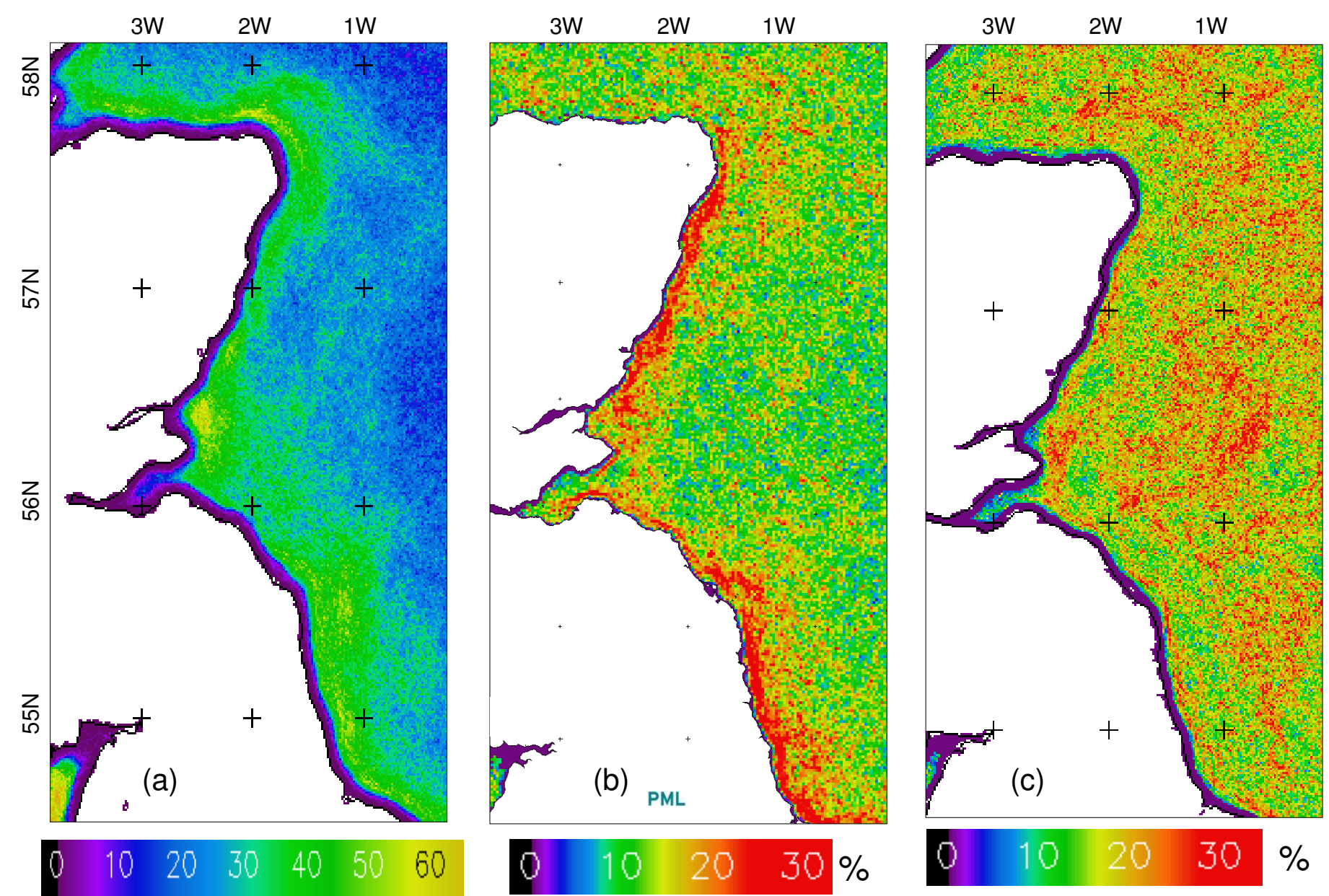

Figure 7. Mean all-seasons front frequency for Aberdeenshire-Firth of Forth: (a) thermal fronts; (b) 300m Chl-a fronts; (c) $1 \mathrm{~km}$ Chl-a fronts. 

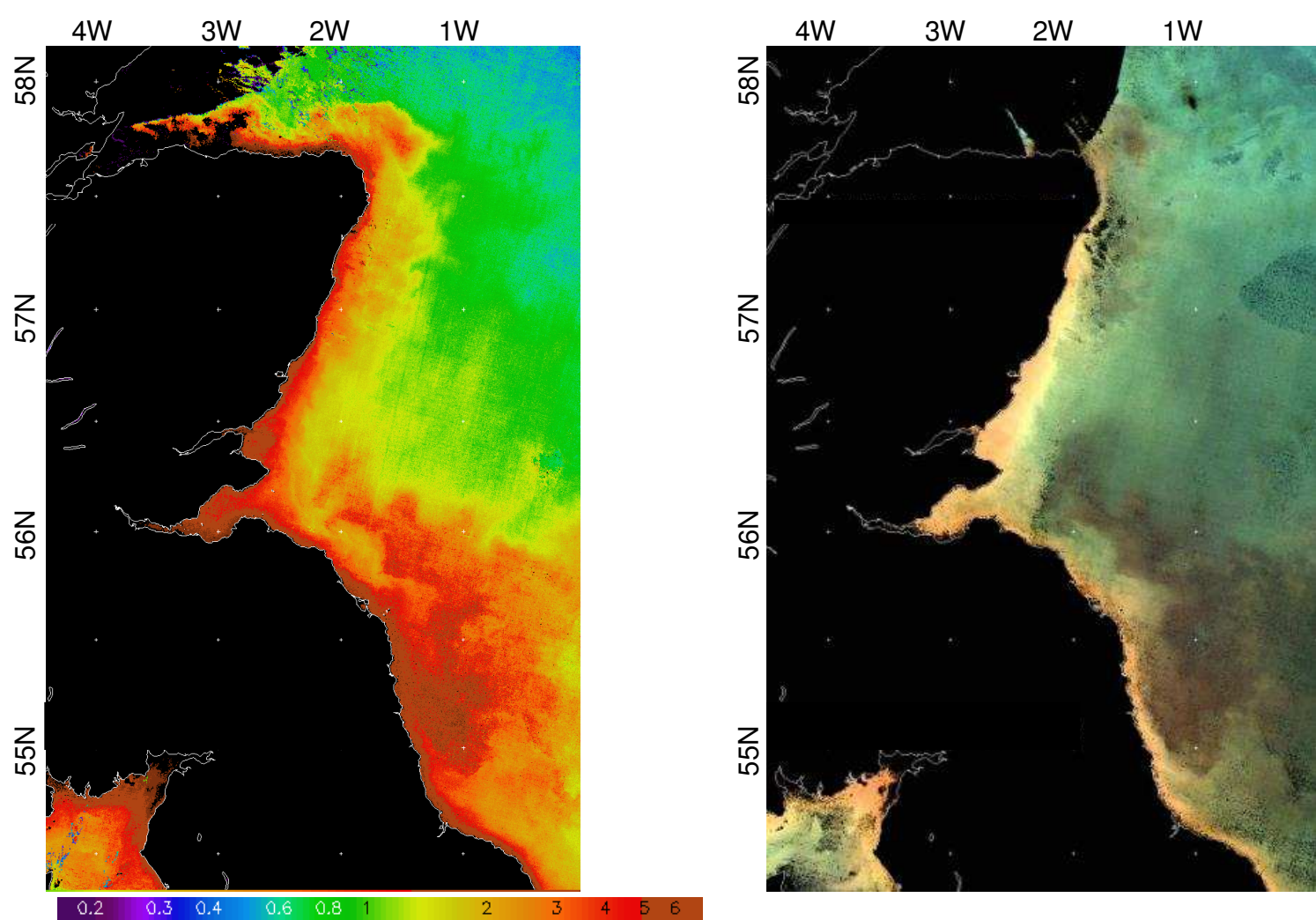

(a)

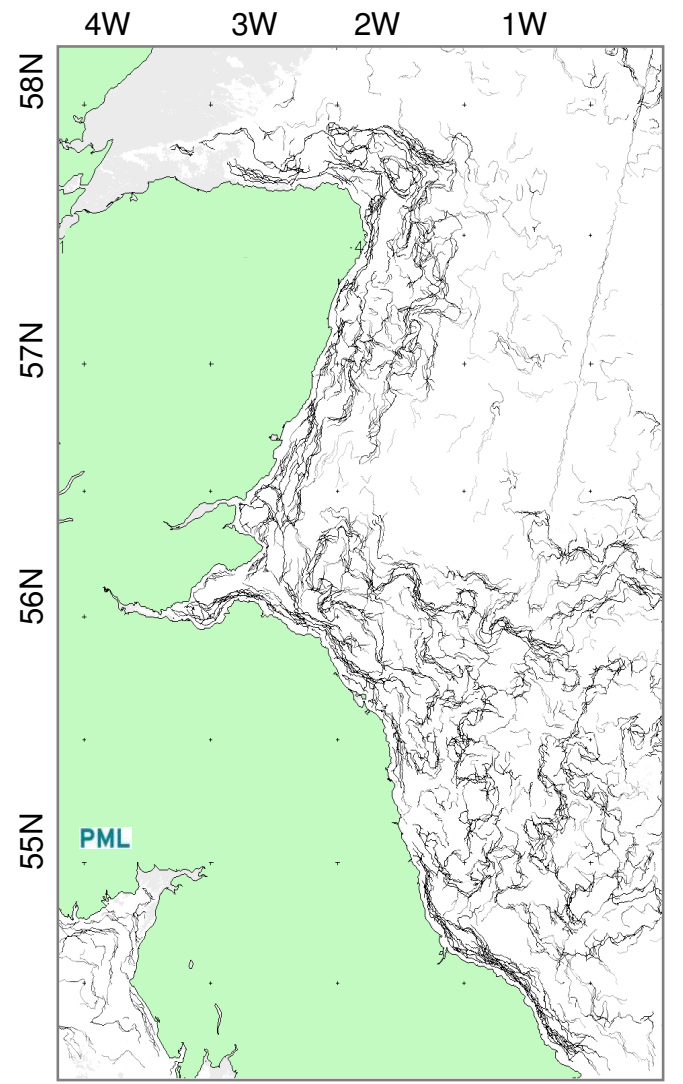

(c)

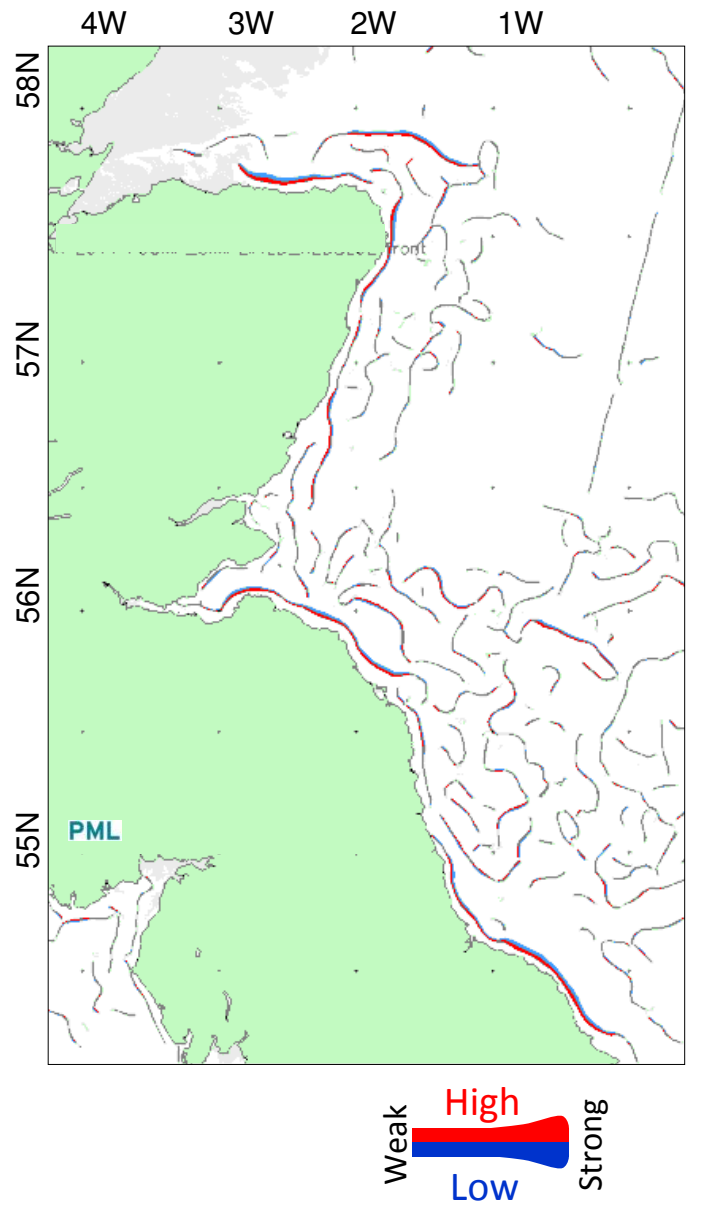

Figure 8. Analysis of colour fronts in Aberdeenshire/Firth of Forth region using 14-21 March 2011 MERIS FR composites: (a) chlorophyll-a; (b) enhanced colour; (c) 300m Chl-a composite front map; (d) simplified Chl-a front map using red-blue to indicate the high-low side of each front. Chlorophyll-a and enhanced colour composites are created using different combinations of ocean colour channels, with the latter version giving a 'true' colour view. Different channels have different missing values, therefore areas with 'no data' are inconsistent between the two versions. 

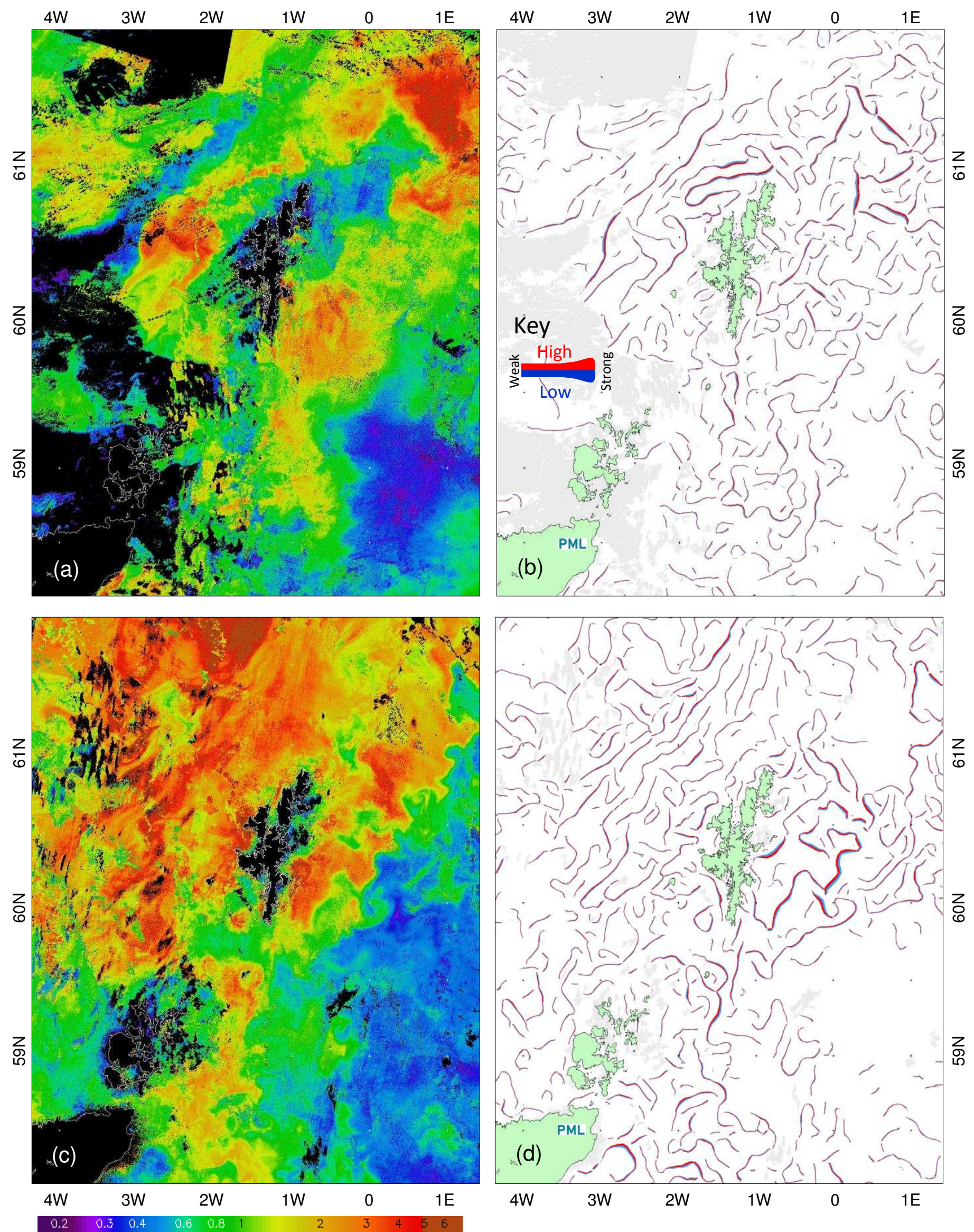

Figure 10. Analysis of colour fronts around Fair Isle using MERIS FR composites: (a) 12-19 Jul. 2010 chlorophyll-a; (b) simplified Chl-a front map; (c) 26 Jun. 03 Jul 2011 chlorophyll-a; (d) simplified Chl-a front map. 

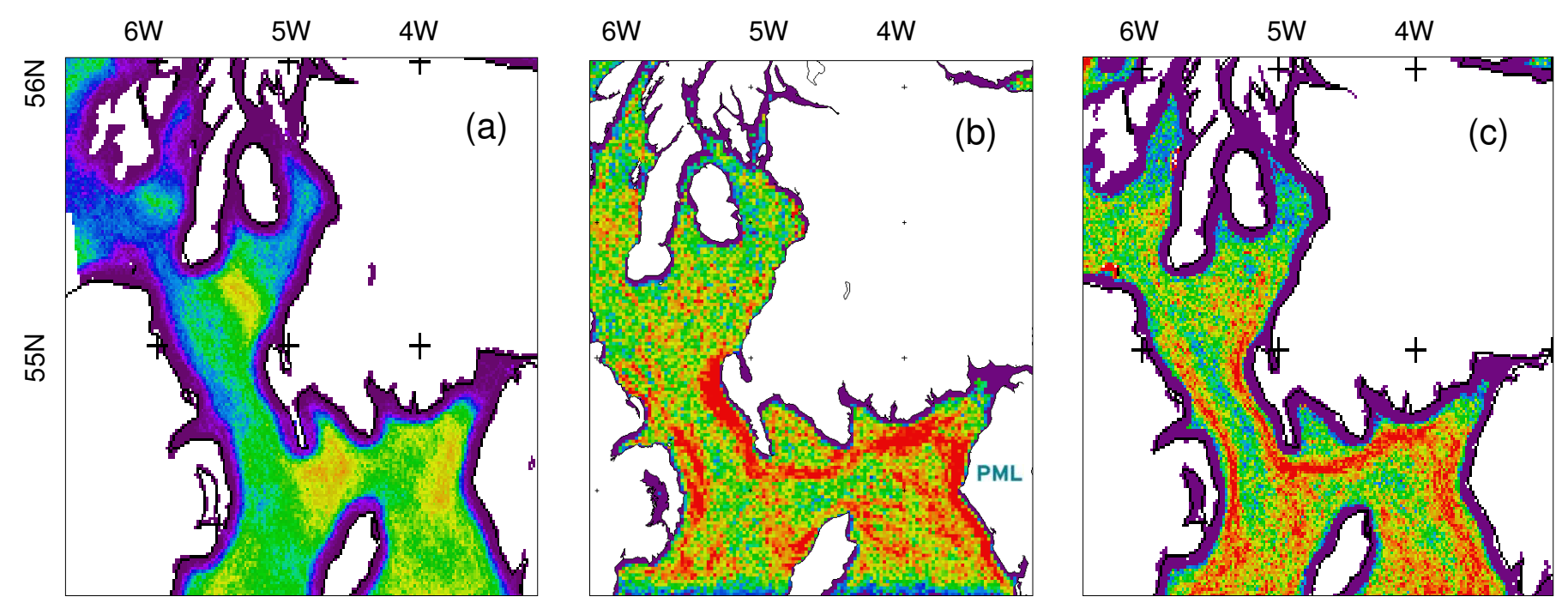

$\begin{array}{llllllll}0 & 10 & 20 & 30 & 40 & 50 & 60 & \%\end{array}$
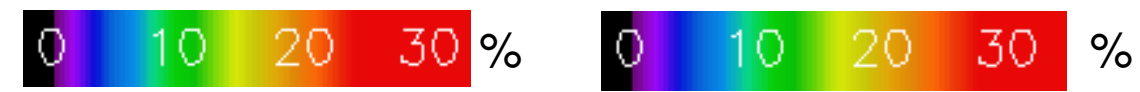

Figure 11. Mean all-seasons front frequency for Galloway peninsula:

(a) thermal fronts; (b) $300 \mathrm{~m}$ Chl-a fronts; (c) $1 \mathrm{~km}$ Chl-a fronts. 


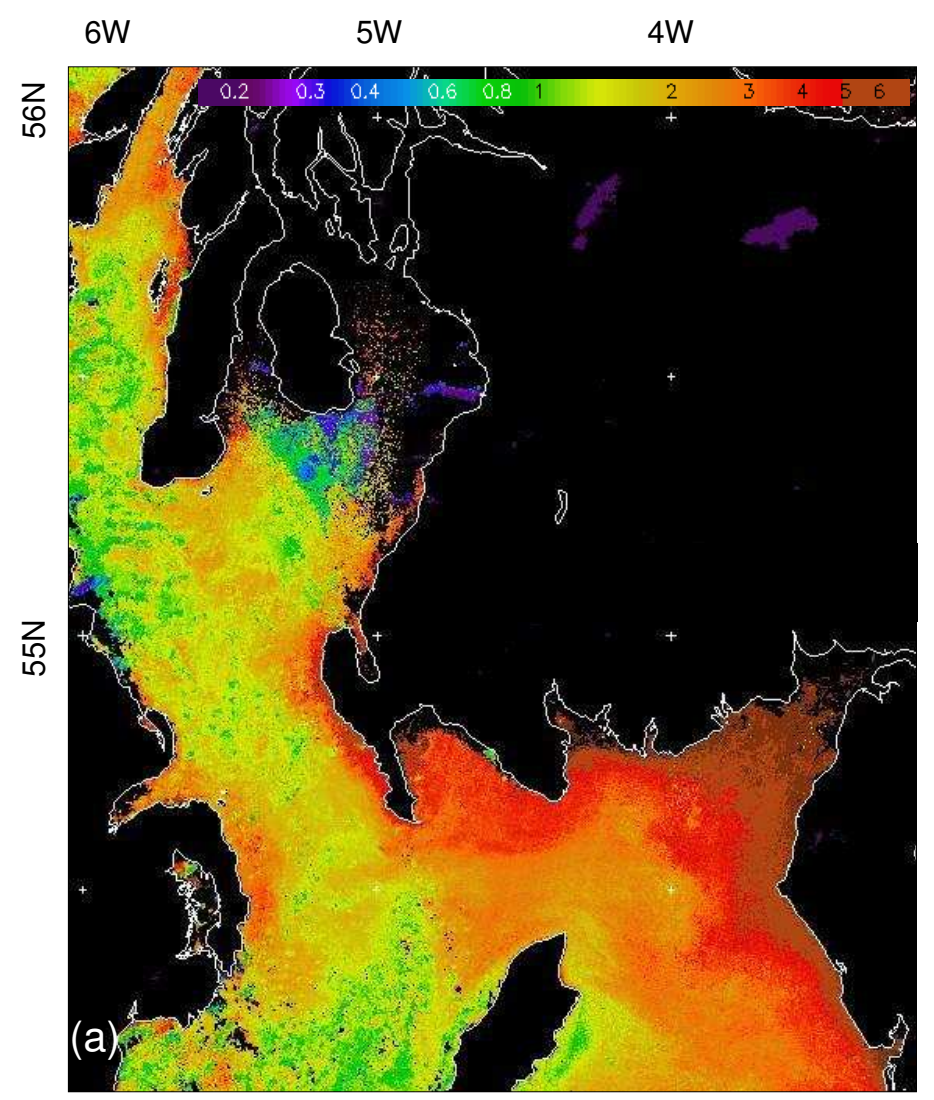

$6 \mathrm{~W}$

$5 W$

$4 W$
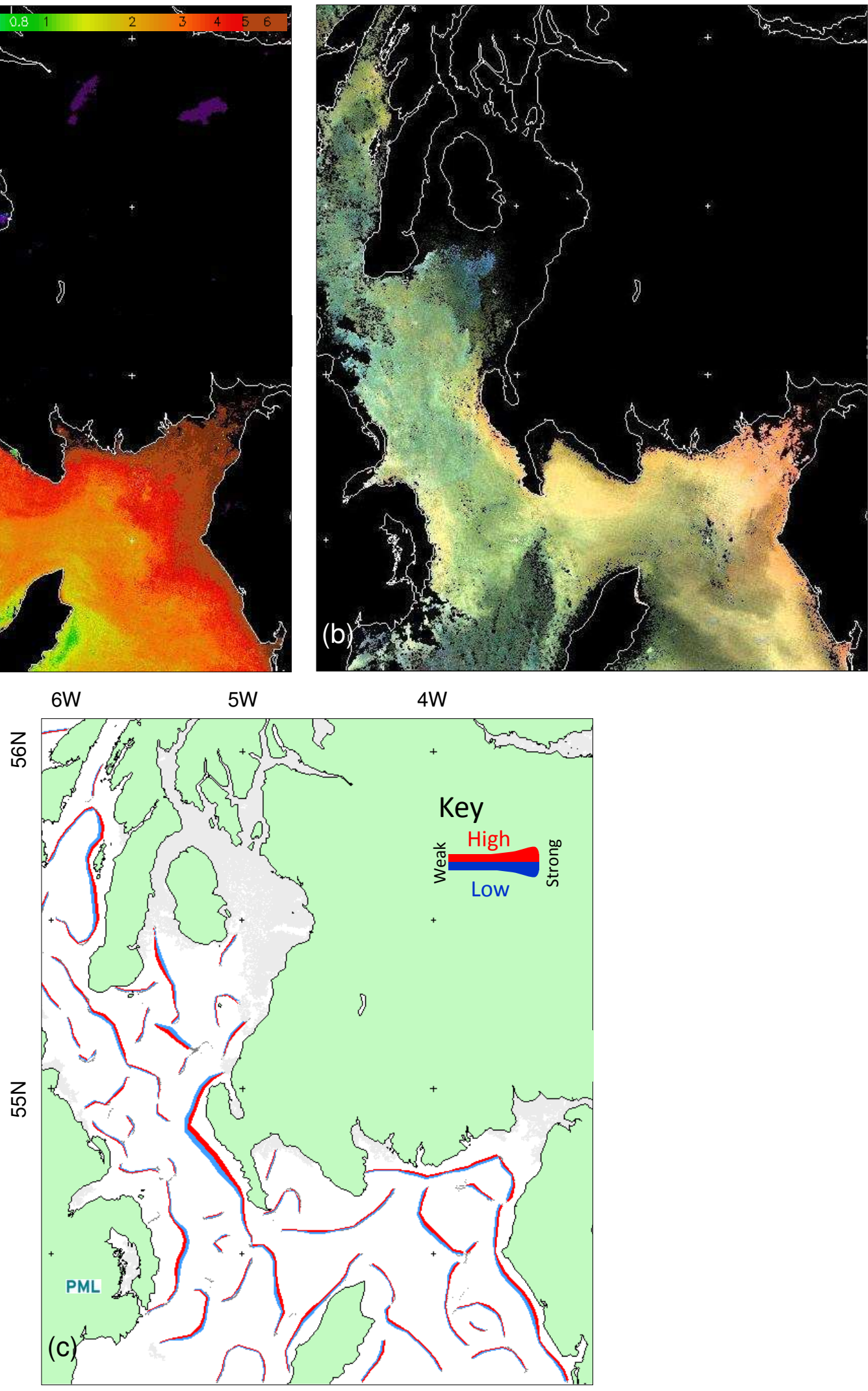

Figure 12. Analysis of colour fronts around Galloway peninsula and Clyde using 22-29 Sep. 2010 MERIS FR composites: (a) chlorophyll-a; (b) enhanced colour; (c) simplified Chl-a front map. 

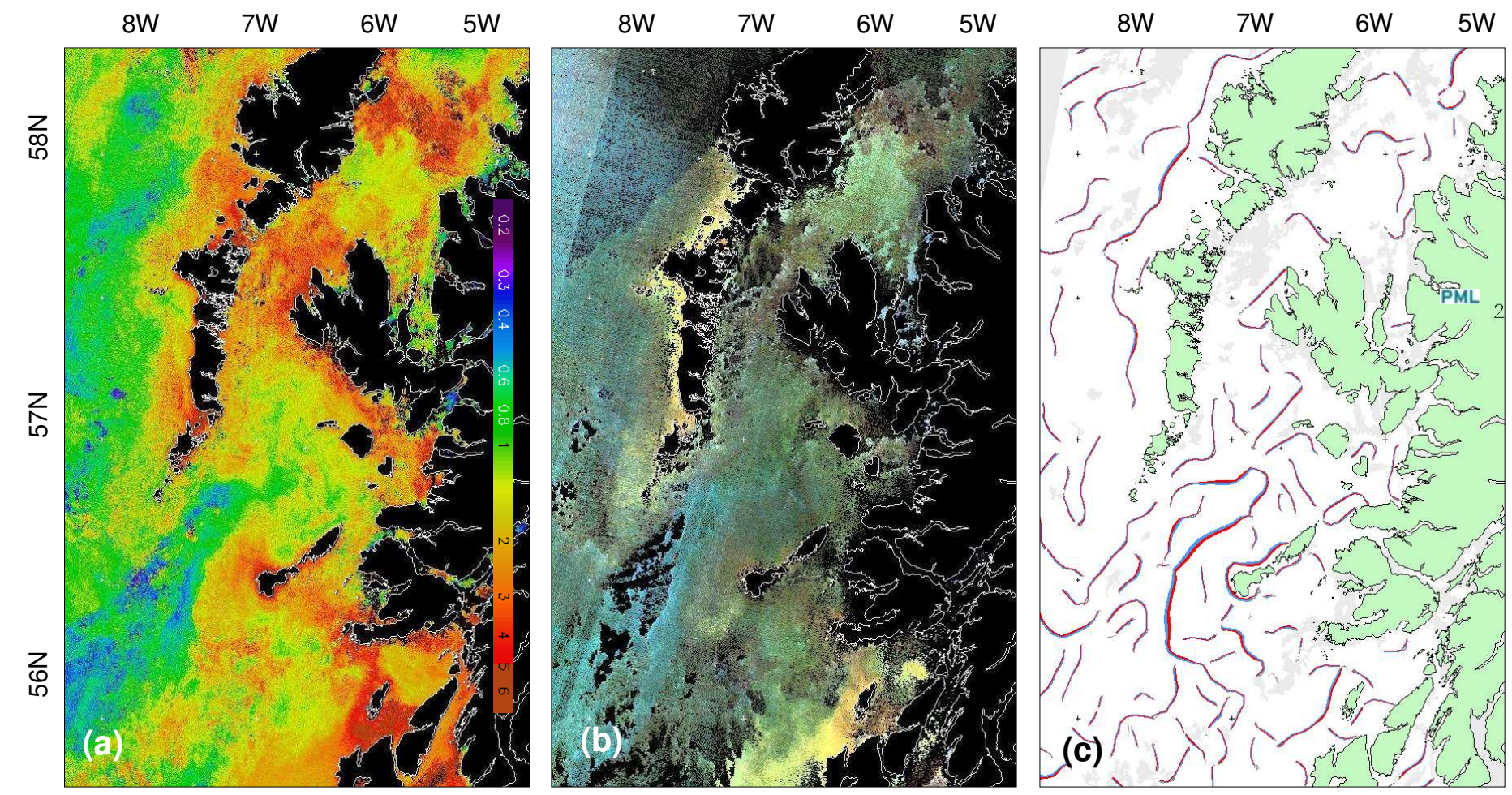

Figure 14. Analysis of colour fronts around Tiree and Hebrides using 23-30 Apr. 2011 MERIS FR composites: (a) Chl-a; (b) enhanced colour; (c) simplified Chl-a front map. 